\title{
Robust Supervision by Integration External and Bond Graph Models of a Desalination System
}

\author{
Abderrahmene sallami ${ }^{1}$, Dhia mzoughi ${ }^{2}$, Hatem allagui $^{3}$, Abdelkader mami $^{4}$ \\ ${ }^{1-4}$ Analysis, Design and Control Systems Laboratory, Faculty of Sciences of Tunis, Tunis El Manar \\ University, Tunis, Tunisia \\ abderrahmenesallami@gmail.com,dhia.mzoughi@gmail.com, hatem.allegui@enit.rnu.tn \\ abdelkader.mami@gmail.com
}

\begin{abstract}
:
This article aims to solve the problem of robust supervision of a reverse osmosis desalination system (RO-DS) with two models, external model and bond graph model. The structure of an industrial system from the point of view of the external model operates according to several modes of operation (degraded and normal). For this external model, we cannot locate the faults since we are talking about a global operation of the system. The possible solution for the development of research was to use the multidisciplinary model called bond graph. This model by its graphic nature and using a unified language makes it possible to model the industrial system element by element from where it helps the user not only to detect the faults but also to locate them when they appear in the system.

The results suggest that the use of the bond graph model for alarm 02 is a reverse osmosis error $\left(R O_{1}\right)$; these phenomena are readable on the bond graph model and can be quantified by equations. The equation of the model of this reverse osmosis $\left(R O_{1}\right)$ is found in the residual equations $\left(r_{5}, r_{6}\right.$ and $\left.r_{7}\right)$, so that these residues will be sensitive to this rupture. The possible solution during research development was to use the bond graph model to supplement information with physical knowledge and to locate faults.

This article also describes the operating safety (by minimizing false alarms and non-detections as well as delays in fault detection) of the desalination system by using the bond graph model described in Linear Fractional Transformation $(L F T)$ form for enable it to manage the robust supervision of a desalination system. An approach based on $(L F T-B G)$ is developed to monitor tank leakage $(\mathrm{Cu})$ and reverse osmosis $\left(R O_{I}\right.$ and $\left.R O_{2}\right)$ faults or valve level $\left(V_{l}\right.$ and $\left.V_{2}\right)$ closures and membrane clogging reverse osmosis $\left(R_{m l}\right.$ and $\left.R_{m 2}\right)$ that can occur in the reverse osmosis desalination system $(R O-D S)$.
\end{abstract}

Keywords: Robust Supervision, Bond Graph model, External model, Desalination unit, Reverse osmosis, Linear Fractional Transformation.

\section{INTRODUCTION}

Industrial systems have become so complex that it becomes necessary to have sophisticated information processing systems where decision-making is inevitable. Supervision of automated systems is at the heart of this issue $[1,6]$. The role of the operator has evolved from management to supervision, and the production tool has become inseparable from its control system, making the understanding of events all the more complex [7, 11]. For the external model, the execution of a service requires the availability of a certain number of resources, and is triggered only after the verification of an activation condition. Although all the resources required to run a service are in perfect working order, it may be impossible to perform the service [12, 16]. However, the failure of certain resources does not imply the unavailability of the service that uses them. Indeed, alternative treatments may be provided. Our research focused on these modeling approaches used to reconfigure the system in the event of a defect. Among the advantages of these functional models is the perfect integration with the behavioral models (bond graph) for the design of the supervision system [17, 21]. We applied the methodology on academic examples and concrete systems. 
The problem to be solved is to use a unifying tool to integrate the functional and behavioral models for the design of the supervision system (surveillance and reconfiguration). The bond graph tool is well suited for this task. From the point of view of surveillance, the causal and structural properties of the bond graph are used for the detection and the isolation of the faults affecting the actuators, the sensors or the physical components of the system. Thus, the availability of the services required for the realization of a mission will be provided by the monitoring algorithm to the graph of management of operating modes. Also, these services are defined by functions that can be generic to leap elements. From a reconfiguration point of view, the graphic properties will be exploited in order to develop the means and conditions for reconfiguring the system.

Due to rapidly evolving industrial technologies and the increasing complexity of certain materials, the supervision of production systems has resulted in significant changes in working methods with less and less manual human tasks for more observation and monitoring.

Indeed, supervision is the set of tools and methods used to drive industrial installations both in normal operation and in the presence of failures. It covers two activities:

- Fault Detection and Isolation (FDI) activity [22, 25];

- Fault Tolerant Control (FTC) activity [26, 28].

This paper is organized as follows: In the second section, we will review various techniques used for the supervision of industrial processes, which will allow us to identify their potential fields of application, their strengths and their weaknesses in order to use the techniques appropriate, as the case may be.

The third section, we will present the supervision of systems by external model with a reminder on some definitions and a presentation of their advantages for the supervision of dynamic systems. For the external model, the execution of a service requires the availability of a certain number of resources, and is only triggered following the verification of an activation condition. Although all the resources needed to run a service are in perfect working order, the execution of the service may be functionally impossible. However, the failure of some resources does not imply the unavailability of the service that uses them. Indeed, alternative treatments can be provided.

The fourth section, we will present first of all the interest of the Bond Graph for the design of supervision system as well as the different analyzes of the physical systems carried out by this model. Subsequently, the use of the bond graph approach with fractional linear transformations (LFT) for the modeling of parametric uncertainties of industrial systems. This BG-LFT approach has consistently generated robust residue indicators. These parametric uncertainties are clearly displayed on the physical model thanks to the causal and structural properties of the bond graphs since the material components are represented by elements $R, C, I, T F$, and $G Y$. Indeed, each uncertain residue generated by this approach is well composed of two parts: the first part corresponds to the evolution of a normal residue $\left(r_{i n}\right)$ and the second part represents the evolution linked to the uncertainty of the parameters $\left(d_{i}\right)$.

For the fifth section we will show the usefulness of the bond graph methodology with integration with the external model to analyze industrial systems. It clearly presents the elements of the physical system taking into account their dynamics. Industrial systems are equipment that produces a coherent mission subset called mode of operation $(M O)$. The transition from one $(M O)$ to another depends on the services provided by the system components. The disadvantage of the external model is that it describes the process components as functions regardless of their dynamics. Hence the interest of the bond graph tool to bridge the limit of the functional approach.

An illustrative example of a reverse osmosis desalination system is developed in the sixth section and motivates the effectiveness of the proposed method.

\section{SUPERVISION SYSTEM}

Supervision is generally defined as a task of controlling and monitoring the execution of an operation or work performed by other agents (men or machines), without going into the details of this execution. We have adopted the definition of the Research Group on Integrated Automation and Human Machine-Driven Systems, which 
stipulates that: supervision is the set of tools and methods used to conduct industrial installations both in normal operation and in the event of faults or disruptions.

A supervisory system is active if it gathers all the events necessary to activate the decision-making see figure 1.

- Real-time: Decision-making will be effective and fast if the situational awareness is complete.

- In delayed time: Decision-making will be taken as appropriate and the analysis of concrete situations allows a formalization of the operations to be created for each provision.

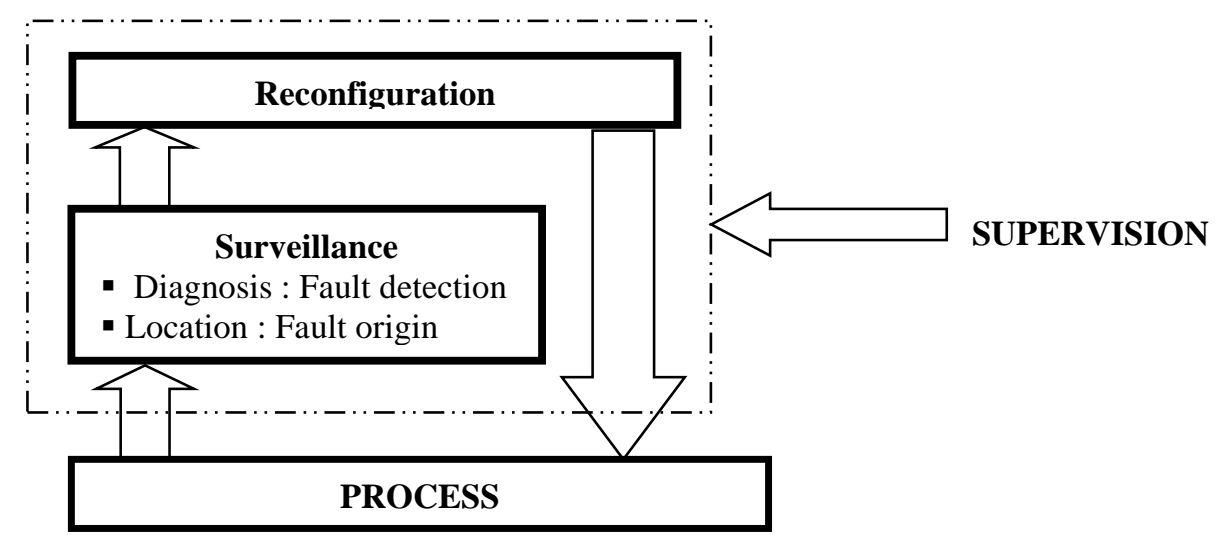

Figure.1. Schema of supervision principle

\section{1. Supervision activities}

Supervision of an automated system can take three modes from Sheridan [29]:

- Normal mode: For this mode the system is stable, its signs are nominal;

- Transition mode: For this mode the system is stable but it switches from one operating state to another state;

- Degraded mode: For this mode the system is unstable, its signs are not nominal.

According to each mode Rasmussen [30] defined two activities which are respectively the activity of supervision and the activity of reconfiguration see figure 2 .

\section{2. Monitoring activities}

Monitoring is responsible for the acquisition of signals from resources. This information is used to reconstruct the actual state of the controlled system and to make the necessary inferences in order to produce additional information to establish operating histories. Surveillance activities are therefore limited to information functions and do not directly affects the model or the process.

\section{3. Reconfiguration activities}

The reconfiguration process is a process of hardware and/or software reorganization of the system. The objective of this reorganization is to be able to ensure production by making a compromise between the production objectives and the state of the system. Indeed, two steps are possible to carry out this operation:

- Static reconfiguration: The complete stop is imposed to make the changes and then restarted,

- Dynamic reconfiguration: The complete shutdown is not imposed; the changes are done during execution, but only the shutdown of the part of the application concerned by the change. Here the term flexibility takes full force in the sense that a modification no longer imposes the complete end of the application but can be done during execution. Distributed applications are built from software resources that can be physically separated but cooperative to perform tasks.

\section{EXTERNAL MODEL FOR SUPERVISION SYSTEM}

Industrial systems consist of a set of interconnected equipment. A hardware failure of one or more of these devices may jeopardize the achievement of some of the objectives for which the system was designed, so users should be warned by generating alarms. The latter must be sufficiently synthetic to express clearly the nature of the failure and its consequences. Research has developed modeling by external model [31]; this model is based on the following notions:

- Concept of services,

- Concept of missions,

- Concept of operating modes.

\section{1. Concept of services}


Industrial systems consist of a set of equipment (heat exchanger, motor, pump, etc.) that are organized in such a way that the systems can meet the objectives for which they were designed.

These devices are arranged in two ways:

- Low level: These are basic services; they are directly interfaced with the process (pumps, valves, tank, sensors ...).

- High level: These are composed services; they consist of basic services (cooling circuits, water booster unit, desalination unit ...).

\section{2. Concept of missions}

Elementary services (of low level) are associated with each other to define so-called composite services; the latter realize what we call a mission. A hardware failure means the unavailability of certain basic services and may call into question the continuation of certain missions.

\section{3. Concept of operating modes}

The missions were the first to take responsibility for managing and managing systems in accordance with the objectives of the specifications. But at a given moment, only a subset of these missions is necessary to meet the objectives set. Each of these subsets is referred to as the operating mode.

An operating mode $(M E i)$ corresponds to a set of service versions represented by $\mathrm{Si}$, this set is the grouping of the subsets that define the desired operating mode, so we have the following relation: $M E i=\left\{S_{1}, S_{2} \ldots \ldots, S_{n}\right\}$.

At a given moment, the process is executed in an operating mode (represented by $M E i$ ), all the operating modes are available and interconnected to perform what we call operating mode management graph.

The request to change from one mode to another mode must be indicated for safety reasons because the system may fall on an operating mode $M E j$ which is not available, hence the necessity of having a logical passage that leads The system on a mode of operation without getting into trouble. This passage is represented by a Boolean variable bij. The set of operating modes and the conditions of passage bij are described by a graph of management of the operating modes and which can be represented in figure 2 .

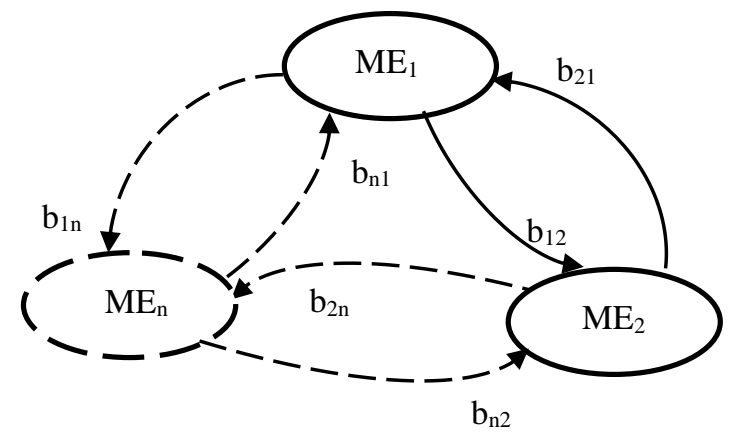

Figure.2. Operating mode management graph

\section{MODEL BOND GRAPH FOR SUPERVISION SYSTEMS}

The Bond Graph modeling tool (BG) was defined by [32], it is a language of graphical representation of physical systems, based on the modeling of the energy phenomena intervening within these systems. This energetic approach makes it possible to underline the analogies that exist between the different fields of physics (mechanics, electricity, hydraulics, thermodynamics, acoustics, etc.) and to represent in a homogeneous form the multidisciplinary physical systems $[33,34]$. In this article, we will present the utility of the bond graph tool for the supervision of industrial systems. In the first part we will give the different approaches using the bond graph for the design of a supervisory system (qualitative and quantitative approach), the second part is devoted to the integration of the external model and the bond graph model for the supervision systems.

\section{2. Interest of the Bond graph}

Bond Graph-based modeling relies mainly on the concept of generalized stress and flux variables that allow the representation of balance sheets and energy exchanges between different elements of a system. In this approach, an energy exchange between two elements is represented by a half-arrow link indicating the direction of the transfer. These half-arrows are called "leaps", each is labeled by a force variable e and a flux variable f. The product of these two variables corresponds to the power "carried" by the leap. We thus obtain directly a set of relations between the magnitudes force and flux used to parameterize the physical system. The notion of power is described by the following relation:

$$
P(t)=e(t) \cdot f(t)
$$


This description is made in terms of components connected together by links through the ports they have, the components are classified by the number of ports they have, they are multiport or n-ports as described in [35]. There are three types of Bond Graphs each used in a particular stage of the design process [36]:

- Bond Graphs with words where the components represent subsystems described by black boxes, this level allows a first decomposition of the system to have an overall view of the energy exchanges implemented;

- Acondal Bond Graphs where the components are indivisible elementary components and whose behavior is known (resistance, inductance, capacitor, etc.), this level is used at an advanced stage of the design process, where the components can be assimilated Perfect elementary components;

- The causal Bond Graphs which allow establishing the equations of the system.

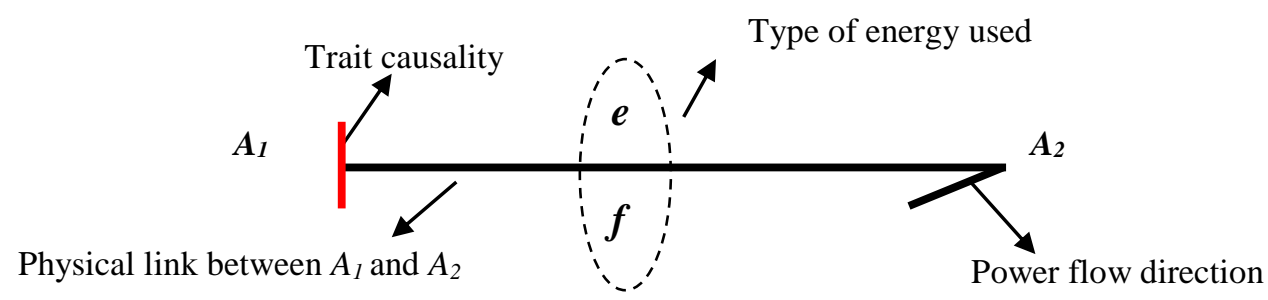

Figure.4. Representation of a physical system by bond graph

\section{3. Generality on modeling by bond graph}

The Bond Graph modeling tool is a graphical representation language of physical systems, based on the modeling of the energy phenomena involved in these systems. This energetic approach makes it possible to underline the analogies that exist between the different domains of physics (electric, hydraulic, mechanics, thermal, etc.) and to represent in a homogeneous form the multidisciplinary physical systems.

The Bond Graph model of a physical system explains the power exchanges (symbolized by links) occurring between different elements (represented by nodes) that produce, dissipate, store or transmit energy. At each node of the Bond Graph are associated one or two relations characteristic of the symbolized physical phenomenon.

We also use generalized energy variables: the moment $\boldsymbol{p}$ (the integral of the effort with respect to time) and the displacement $\boldsymbol{q}$ (the integral of the flux with respect to time).

The following table 1 indicates the equivalence of the generalized variables in physical domains.

Table1: Equivalences of generalized variables in physical domains

\begin{tabular}{|c|c|c|c|c|}
\hline Field & Effort (e) & Flow (f) & Moment (p) & Displacement (q) \\
\hline Electric & Voltage U (V) & Current I (A) & Flow (A/s) & Charge $\mathrm{q}(\mathrm{C})$ \\
\hline Hydraulic & Pressure P (Not) & Flow rate $\mathrm{Q}\left(\mathrm{m}^{3} / \mathrm{s}\right)$ & Impulse $\left(\mathrm{Ns} / \mathrm{m}^{2}\right)$ & Volume V $\left(\mathrm{m}^{3}\right)$ \\
\hline $\begin{array}{l}\text { Mechanics of } \\
\text { Translation }\end{array}$ & Force F (N) & Speed V (m/s) & Moment P (N.s) & Shifting linear $\mathrm{X}(\mathrm{m})$ \\
\hline $\begin{array}{c}\text { Rotation } \\
\text { Mechanics }\end{array}$ & Torque $\mathrm{T}(\mathrm{Nm})$ & $\begin{array}{l}\text { Angular velocity } \\
(\mathrm{rad} / \mathrm{s})\end{array}$ & $\begin{array}{c}\text { Angular moment } \\
\text { (N.s) }\end{array}$ & $\begin{array}{c}\text { Angular } \\
\text { displacement (rad) }\end{array}$ \\
\hline Thermal & Temperature $\mathrm{T}\left(\mathrm{C}^{\circ}\right)$ & Exchange rate & Not used & Load quantity Q (J) \\
\hline
\end{tabular}

We use the elements to represent phenomena that link the generalized variables. We can separate them into three categories, the active elements, the passive elements and the detector elements.

Table 2 summarizes the bond graph elements with examples in some physical domains. 
Table 2: The basic elements of bond graph

\begin{tabular}{|c|c|c|}
\hline Elements & Symbols & Generic law \\
\hline \multirow[b]{2}{*}{ Actives elements } & $7 \mathrm{Se}$ & e independent of $\mathbf{f}$ \\
\hline & $7 \mathrm{Se}$ & e independent of $\mathbf{f}$ \\
\hline \multirow{3}{*}{ Actives elements } & $7 \mathrm{R}$ & $\Phi_{\mathrm{R}}(\mathbf{e}, \mathbf{f})=\mathbf{0}$ \\
\hline & $7 \quad I$ & $\Phi_{I}(\mathbf{f}, \mathbf{p})=\mathbf{0}$ \\
\hline & $7 \mathrm{C}$ & $\Phi c(e, q)=0$ \\
\hline \multirow[b]{2}{*}{ Detectors elements } & $\rightarrow \mathrm{De}$ & \\
\hline & $\longrightarrow$ Df & \\
\hline
\end{tabular}

To couple the previously presented elements, we use junctions. Four types of junctions are defined. These are the $0,1, \mathrm{TF}$ (transformer) and GY (gyrator) junctions.

- Junctions 1 are iso flow junctions;

- Junctions 0 are iso efort junctions;

- Junction TF transform the variables effort-effort, flow-flow ;

- Junction GY transform the variables effort-flow, effort-flow.

Table 3 presents the symbol and the generic law of each type of junctions.

Table 3: Generic law of each type of junctions

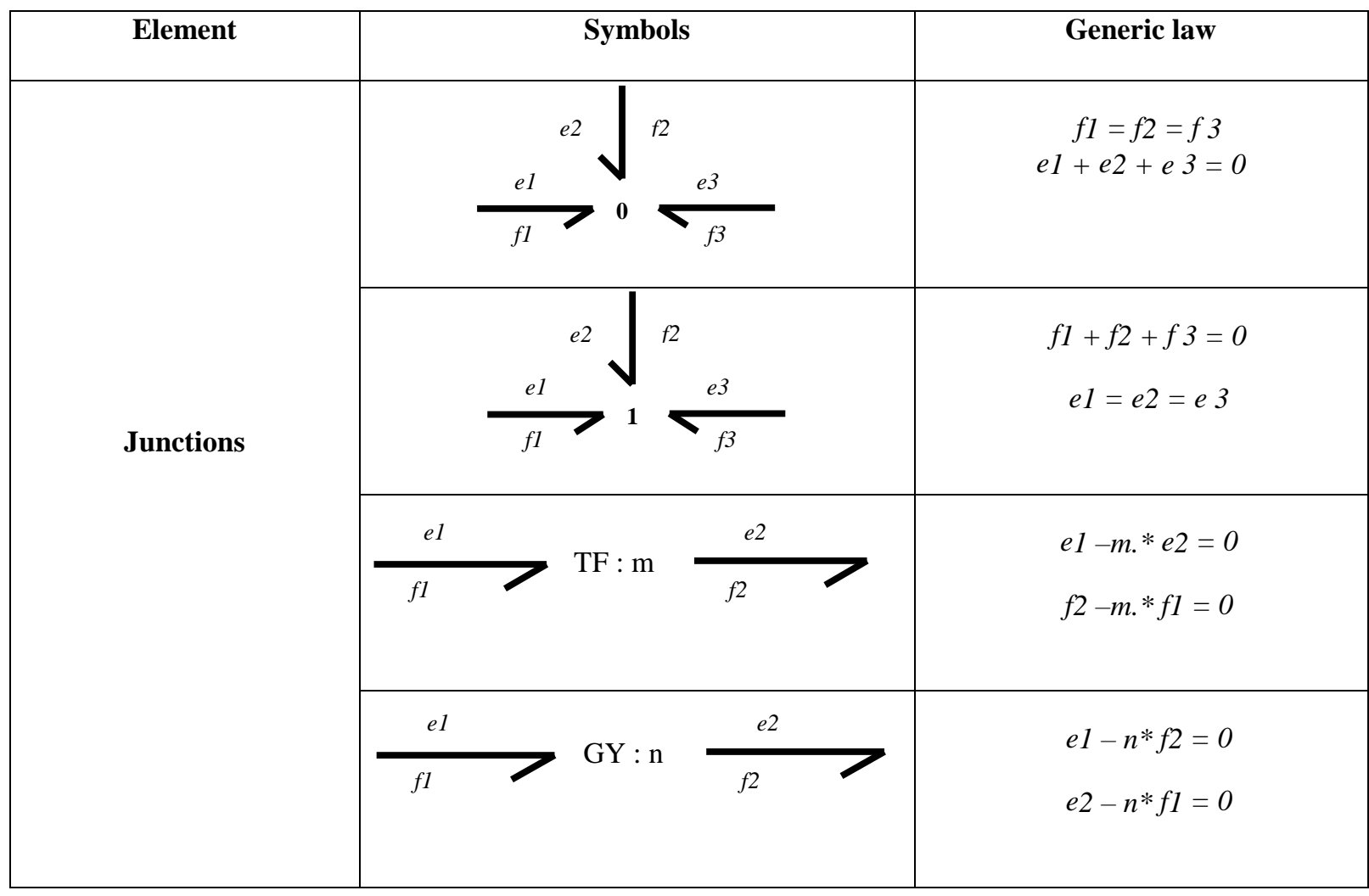


In this article, we study the modeling of the system involving hydraulic energy. We limit to weakly compressible liquids. Table 4 below shows the main characteristics of a hydraulic system.

Table 4: Characteristic of a hydraulic system

\begin{tabular}{|c|c|}
\hline Notion & Descriptions \\
\hline Effort $\boldsymbol{P}$ & $\mathrm{P}=$ Pressure (Pascal) \\
\hline Flow $\boldsymbol{f}$ & $\mathrm{Q}=$ Volume flow rate $\left(\mathrm{m}^{3} / \mathrm{s}\right)$ \\
\hline Moment $\boldsymbol{P}$ & Hydraulic moment; Integral pressure \\
\hline Displacement $\boldsymbol{q}$ & $\mathrm{P}=$ Volume $\left(\mathrm{m}^{3}\right)$ \\
\hline Power & $\mathrm{P}) . \mathrm{Q}(\mathrm{t})(\mathrm{w})$ \\
\hline Energy $\boldsymbol{E}$ & Ec $=(\mathrm{J})$ kinetic energy; EP $=(\mathrm{J})$ Potential Energy \\
\hline Element $\boldsymbol{R}$ & Restriction $\left(\mathrm{Pa} / \mathrm{m}^{3} / \mathrm{s}\right)$ \\
\hline Element $\boldsymbol{I}$ & Inertia $\left(\mathrm{Pa} / \mathrm{m}^{3} / \mathrm{s}^{2}\right)$ \\
\hline Element $\boldsymbol{C}$ & Hydraulic accumulator $\left(\mathrm{m}^{3} / \mathrm{Pa}\right)$ \\
\hline
\end{tabular}

\section{4. Robust supervision systems using the bond graph}

Fractional linear transformations (LFT) are generic objects widely used in the modeling of uncertain systems. The universality of fractional linear transformations is due to the fact that any rational expression can be written in this form [37]. This form of representation is widely used for the synthesis of control laws of uncertain systems using the principle of $\mu$-analysis. It consists of separating the nominal part of a model from its uncertain part as shown in figure 5. The nominal values are grouped together in an augmented matrix denoted M, supposed to be proper, and the uncertainties whatever their type (structured and unstructured parametric uncertainties, modeling uncertainties, measurement noises, etc.) are combined in a matrix $\Delta$ of structure diagonal shown in figure $2[38,40]$.

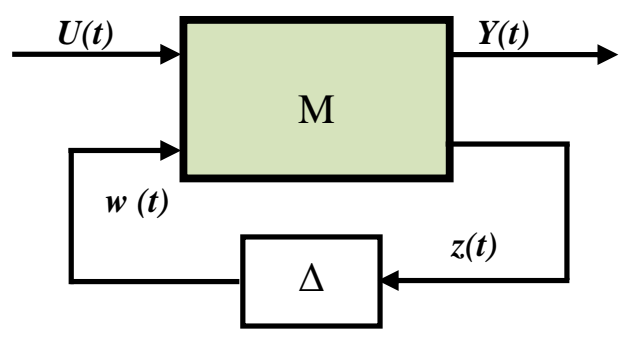

Figure.5. Representation LFT

All industrial systems can be modeled by a hop graph model according to figure 6 . Indeed, the input signal is modeled by a source of effort $(\mathrm{Se})$ or a source of the flux $(\mathrm{S} f)$, the whole system is Modeled by resistive elements $(R)$ and storage elements $(I$ or $C$ ) while the detectors are modeled by elements of the detectors ( $D e$ or $D f)$. 


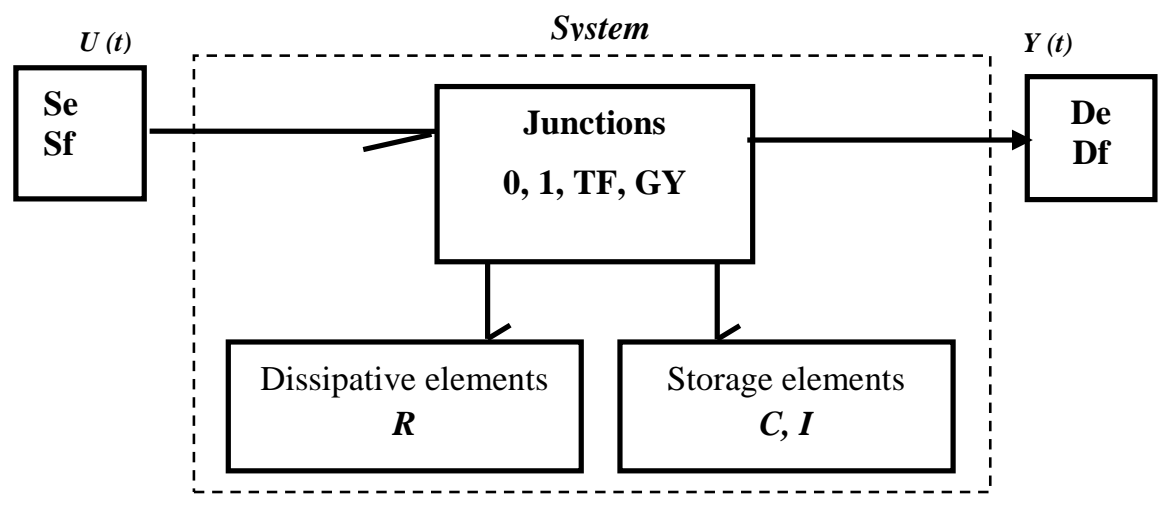

Figure.6. Industrial system described by bond graph

\section{4. 1. Modeling BG elements LFT}

Turning the LFT form requires that the model be clean and observable C. Sie Kam. The bond graph methodology allows for manipulation of causal check these properties directly on the bond graph model.

Property 1: A bond graph model is proper if and only if it contains no dynamic component derived causality when it is in full preferential causality, and conversely C. Sweat \& al..

Property 2: A bond graph model is structurally observable in a state if and only if the following conditions are met:

- On the bond graph model integral causality, there is a causal path between all dynamic elements I and C in full or causality De and Df sensors;

- All dynamic components $I$ and $C$ admit a causal derivative on the bond graph model preferred derivative causality. If $I$ or $C$ dynamic elements remain integral causality, dualisation sensors $D e$ and $D f$ should help put them in derivative causality.

The modeling of uncertain parameter to linear systems was developed in $C$. Sie Kam, we invite the reader to view the references for details on the modeling of uncertain BG elements $(R, I, C, T F$ and $G Y)$.

We therefore limit this part to show the two methods of modeling uncertain BG elements and the advantages of BG-LFT for robust supervision.

\section{4. 1. 1. BG element with additive uncertainty}

By introducing an uncertainty of additively on e.g. element $R$ in causality resistance is obtained:

$$
e_{R}=\left(R_{n}+\Delta R\right) f_{R}=R_{n} f_{R}+\Delta R_{n} f_{R}=e_{n}+e_{i n c}
$$

With:

- $R_{n}$ : The nominal value of the element $\mathrm{R}$;

- $\Delta R$ : Additive uncertainty parameter;

- $e_{R}$ and $f_{R}$ : Represent respectively the effort and the flow in the element $R$;

- $e_{n}$ and $e_{\text {inc }}$ : Respectively represent the effort made by the nominal setting and effort introduced by the additive uncertainty.

Equation (2) clearly shows that the effort introduced by. $\Delta R$ additive uncertainty is independent of the nominal value of the parameter $R n$. This form of representation is valid for linear systems with constant parameters. One can consider extending it to model complex systems. 


\section{$\checkmark$ Resistive element with additive uncertainty}

The bond graph model equivalent mathematical model of equation (2) is given in figure 7.

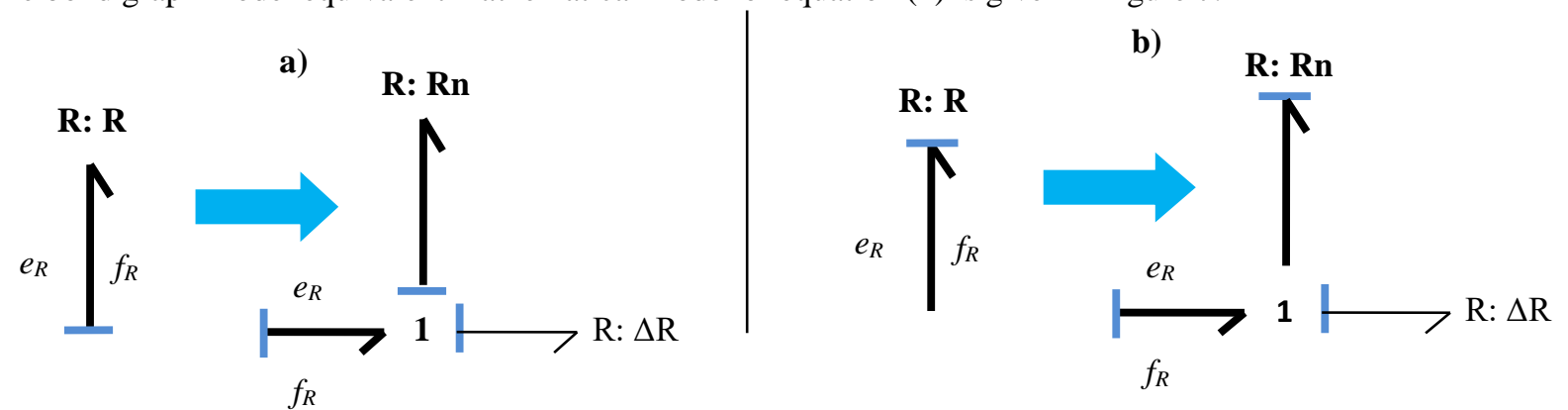

Figure.7. a) Model BG-LFT model of an element resistance with additive uncertainty, b) BG-

LFT model of an element conductance with additive uncertainty

$\checkmark \quad$ Storage elements with an additive uncertainty

$>\quad$ Parts I and C derived causality

The bond graph model equivalent mathematical model of equation (2) is given in figure 8 .

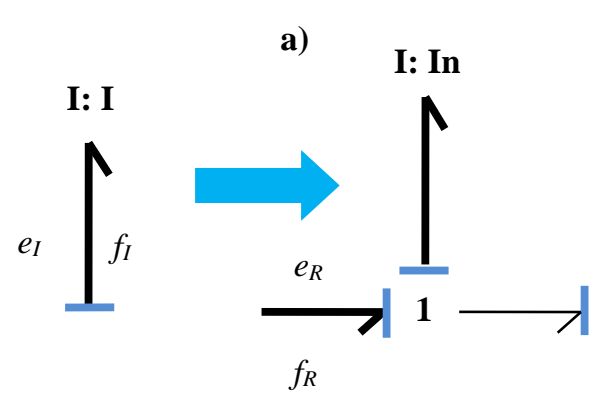

I: $\Delta \mathrm{I}$

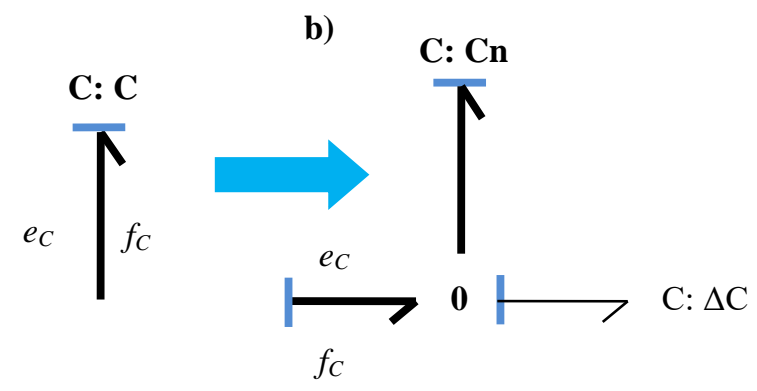

Figure 8.a) BG-LFT model of an element $\boldsymbol{I}$ in derivative causality with additive uncertainty, b)

BG-LFT model of an element $\boldsymbol{C}$ in derivative causality with additive uncertainty

$>\quad$ Parts I and C in integral causality

The bond graph model equivalent mathematical model of equation (2) is given in figure 9.

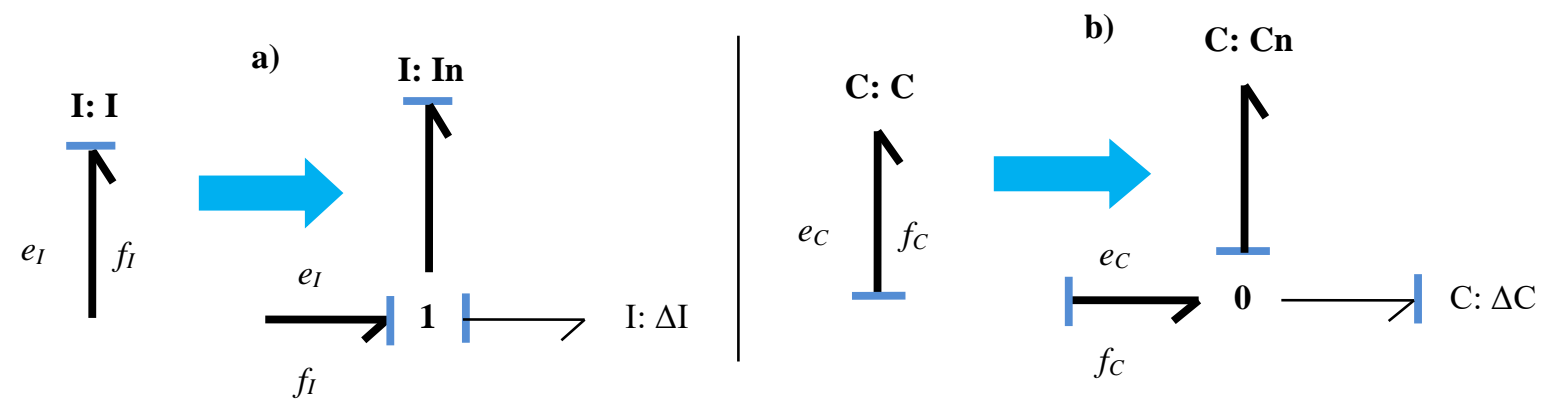

Figure 9.a) BG-LFT model of an element $\boldsymbol{I}$ in integral causality with additive uncertainty, b) BG-LFT model of an element $\mathbf{C}$ in integral causality with additive uncertainty

\section{4. 1. 2. BG element with multiplicative uncertainty}

The introduction of a multiplicative uncertainty on e.g. element $R$ in causality gives resistance:

$$
e_{R}=R_{n}\left(1+\beta_{R}\right) f_{R}=R_{n} f_{R}+\beta_{R} R_{n} f_{R}=e_{n}+e_{n}+\beta_{R} e_{n}=e_{n}+e_{i n c}
$$

With: 
- $\quad R_{n}$ : The nominal value of the element $R$;

- $\quad \beta_{R}$ : The multiplicative uncertainty parameter;

- $\quad e_{R}$ et $f_{R}$ : Represent respectively the effort and the flow in the element $R$;

- $\quad e_{n}$ et $e_{i n c}$ : Respectively represent the effort made by the nominal setting and effort introduced by the additive uncertainty.

$\checkmark \quad$ Resistive element with a multiplicative uncertainty

The bond graph model equivalent mathematical model of equation (3) is given in figure 10.

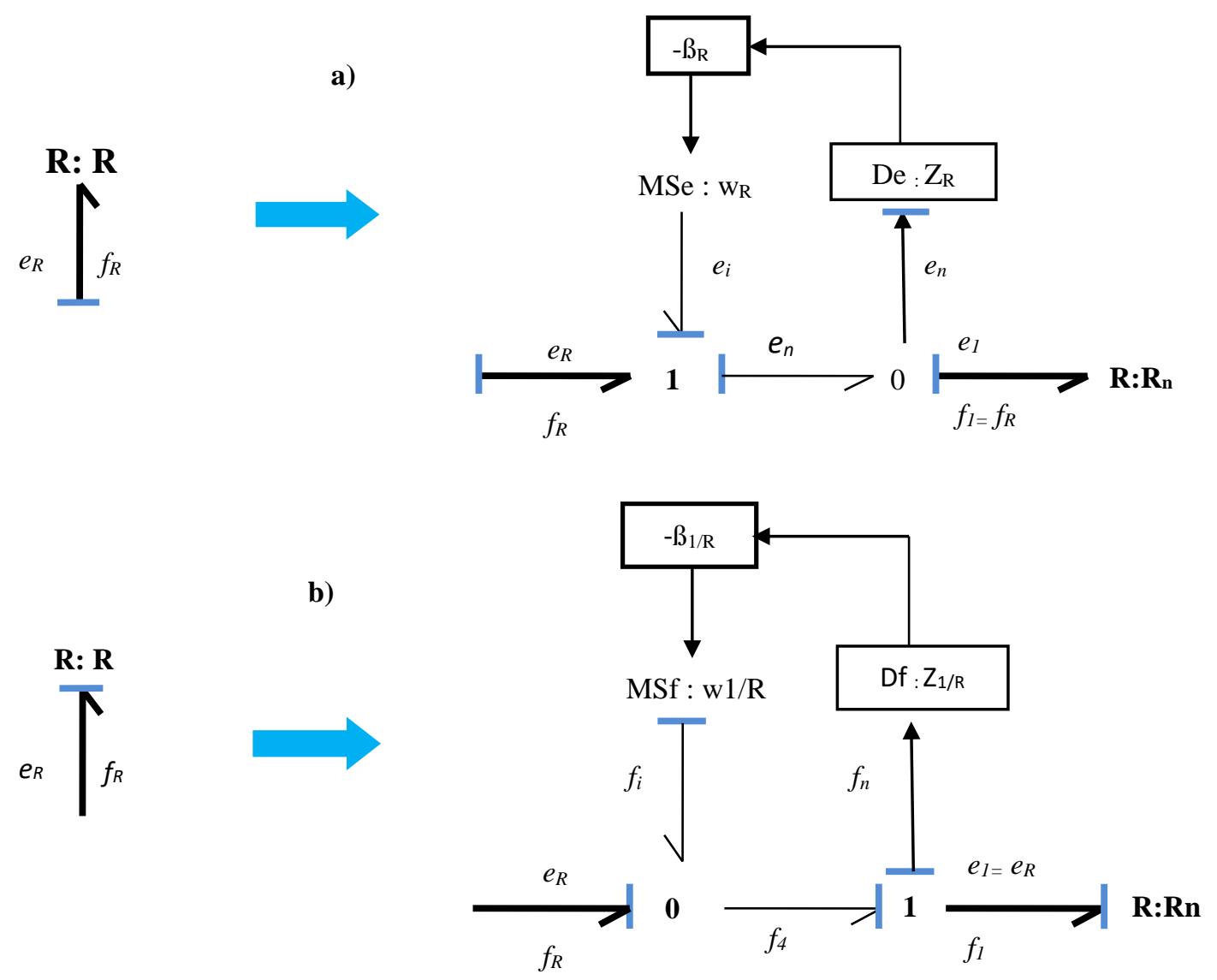

Figure10.a) BG-LFT model of an element resistance with multiplicative uncertainty, b) BG-

LFT model of an element conductance with multiplicative uncertainty.

$\checkmark \quad$ Storage elements with an multiplicative uncertainty

$>\quad$ Parts I and C derived causality

The bond graph model equivalent mathematical model of equation (3) is given in figure 11.

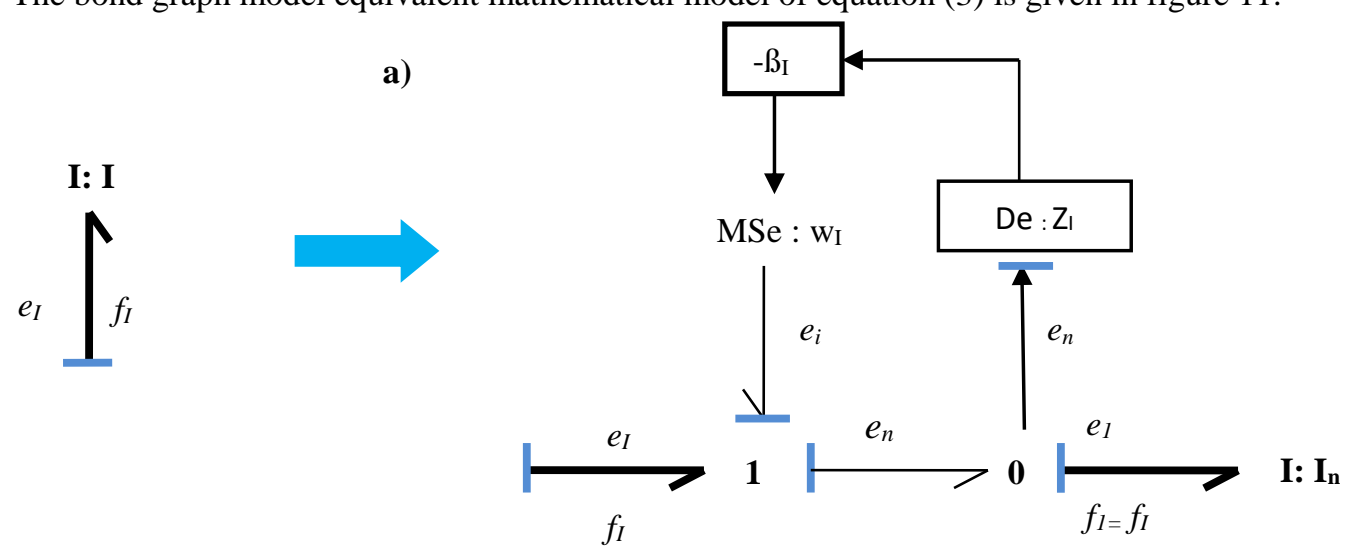




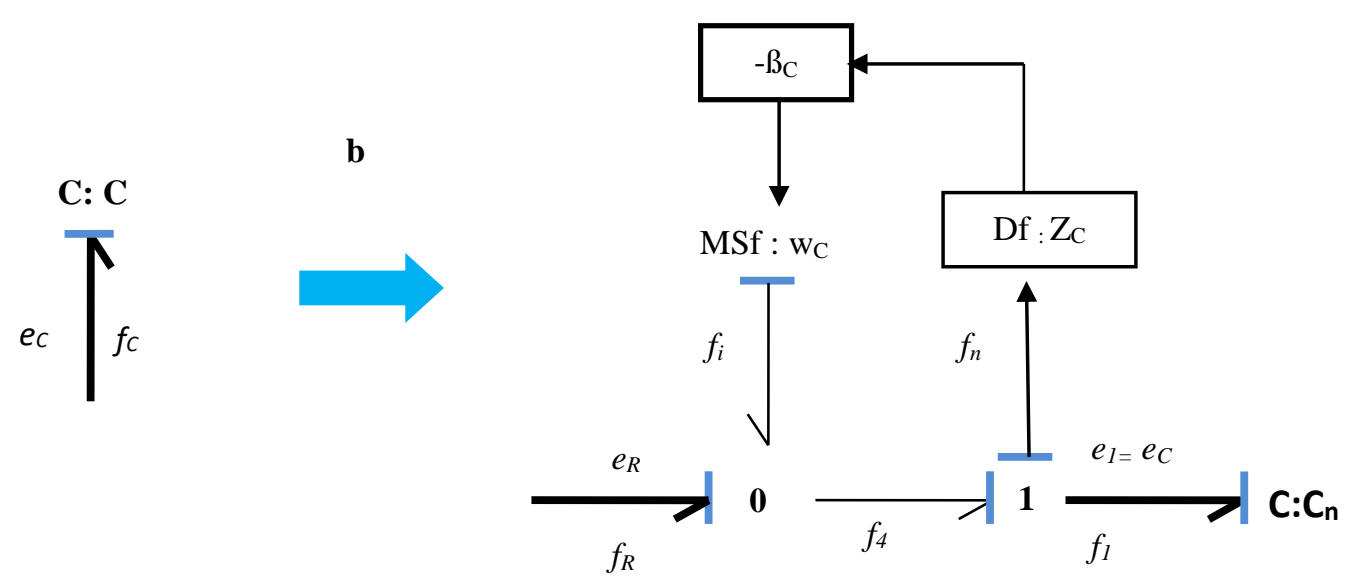

Figure 11.a) BG-LFT model of an element $\boldsymbol{I}$ in derivative causality with multiplicative uncertainty, b) BG-

LFT model of an element $\boldsymbol{C}$ in derivative causality with additive uncertainty

\section{Parts I and C integral causality}

The bond graph model equivalent mathematical model of equation (3) is given in figure 13.

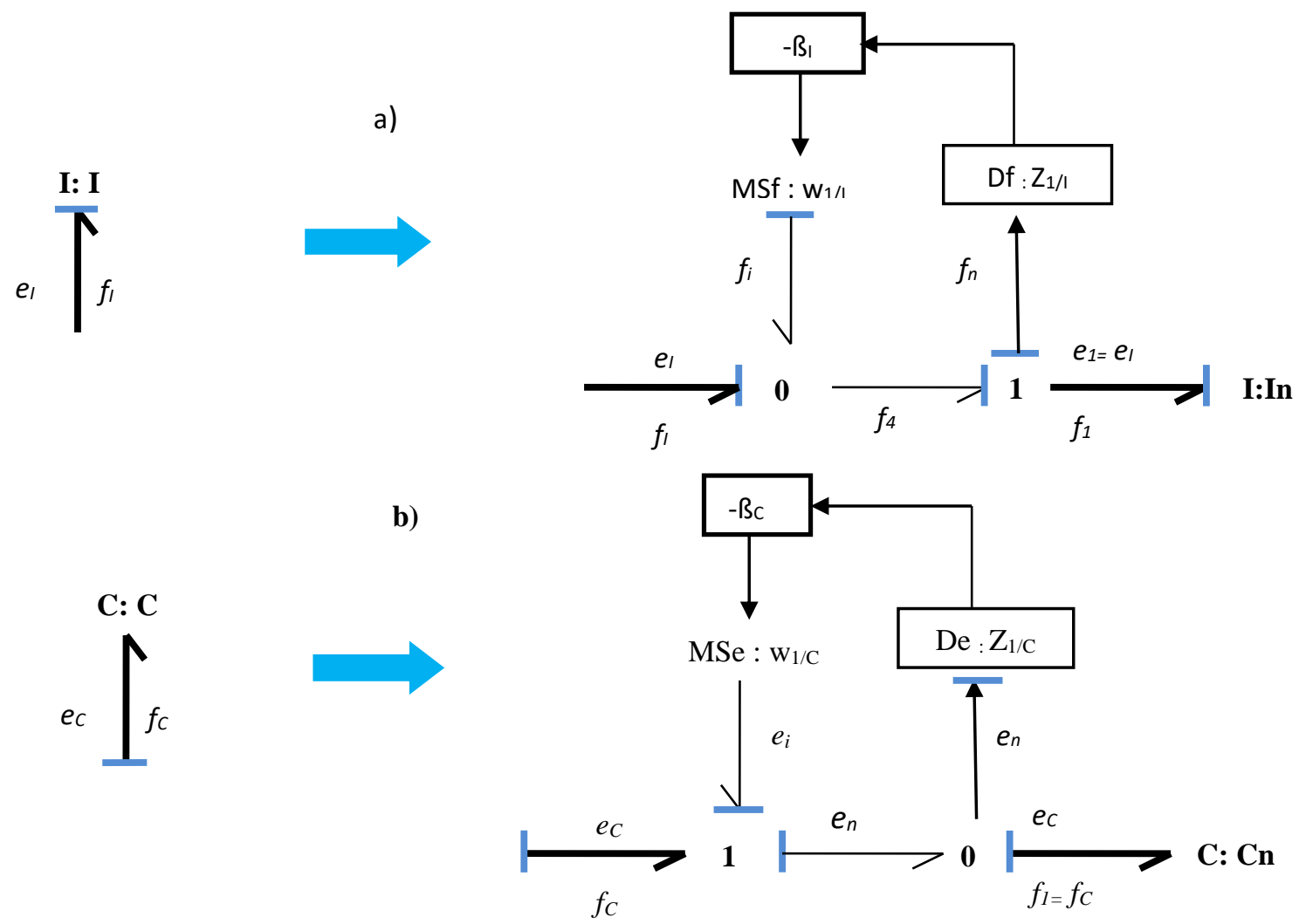

Figure 13.a) BG-LFT model of an element $\boldsymbol{I}$ in integral causality with multiplicative uncertainty, b) BG-LFT model of an element $\mathbf{C}$ in integral causality with multiplicative uncertainty

Full BG-LFT can then be represented by the diagram in figure 14 . 


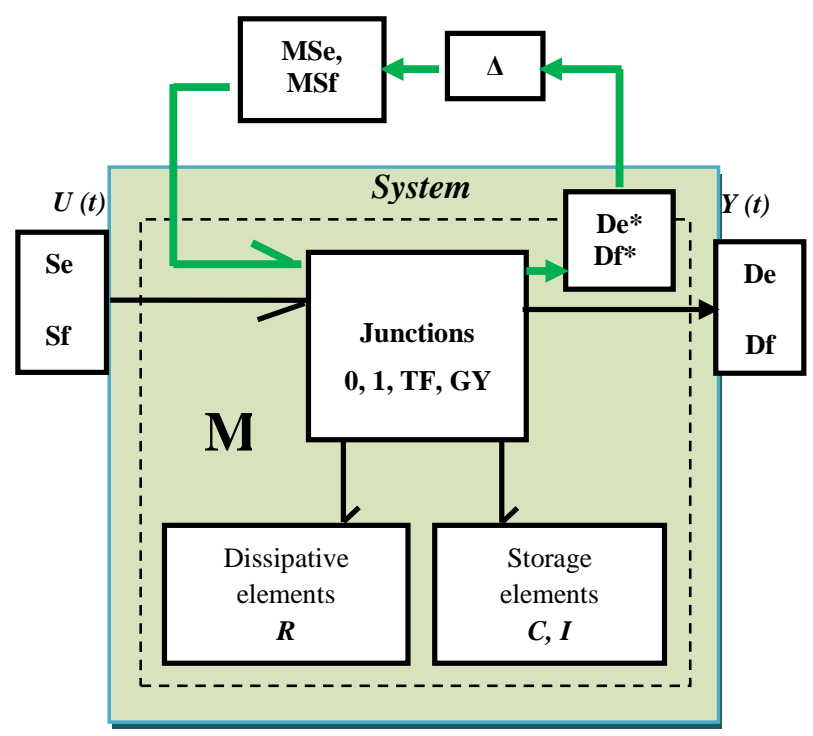

Figure.14. Representation of a BG-LFT

\section{5. Generate robust residuals}

The generation of robust analytical redundancy relations from a clean bond graph model, observable and over determined is summarized by the following steps:

- $I^{\text {st }}$ step: Checking the status of the coupling on bond graph deterministic model derived preferential causality; if the system is over determined, then continue the following steps;

- $2^{\text {nd }}$ step: The bond graph model is made into LFT;

- $3^{\text {rd }}$ step: The symbolic expression of analytical redundancy relationships (ARRs) is inferred from equations junctions. This first form will be expressed by:

$\checkmark$ For a junction 0:

$$
\begin{gathered}
\sum b_{i} \mathrm{f}_{\mathrm{inc}}+\sum \mathrm{Sf}+\sum \mathrm{w}_{\mathrm{i}} \\
\checkmark \quad \text { For a junction 1: } \\
\sum b_{i} e_{i n c}+\sum S e+\sum w_{i}
\end{gathered}
$$

With the sum of sources flows due to the junction 0 , the sum of the flow sources related to junction $1, b= \pm 1$ depending on whether the half-arrow into or out of the junction and $e_{i n c}$ and purpose are unknown variables.

- $4^{\text {th }}$ step: The unknown variables are eliminated by browsing the causal paths between sources and detectors or unknown variables;

- $5^{\text {th }}$ step: After removing the unknown variables, are uncertain as ARRs (5):

ARRs: $\Phi\left(\sum S e, \sum S f, D e, D f, \widetilde{D} e, \widetilde{D} f, \sum w_{i}, R_{n}, I_{n}, C_{n}, T F_{n}, G Y_{n}\right)$

Or:

- $T F_{n}$ and $G y_{n}$ are nominal elements $T F$ and $G Y$;

- $R_{n}, C_{n}$ and $I_{n}$ are nominal elements $R, C$ and $I$;

- $\sum w_{i}$ is the sum of modulated inputs corresponding to uncertainties on the junction-related items.

\section{INTEGRATION OF EXTERNAL MODELS AND BOND GRAPH MODELS FOR SYSTEM SUPERVISION}

The external models allow structuring the operation of the industrial processes according to several modes of exploitation [41, 42]. This model is based on the notions of services, modes of operation and missions. The logical conditions for switching from one operating mode to another are described by a state-transitions graph called a management graph of operating modes figure 14 .

The main limitations of the functional approach concern the ambiguity introduced by the notion of function and the absence of physical considerations of the process. The Bond Graph tool appears as a complementary tool for 
these tasks. The first works that combined the external models and the Bond Graph models are the work of [43, 45].

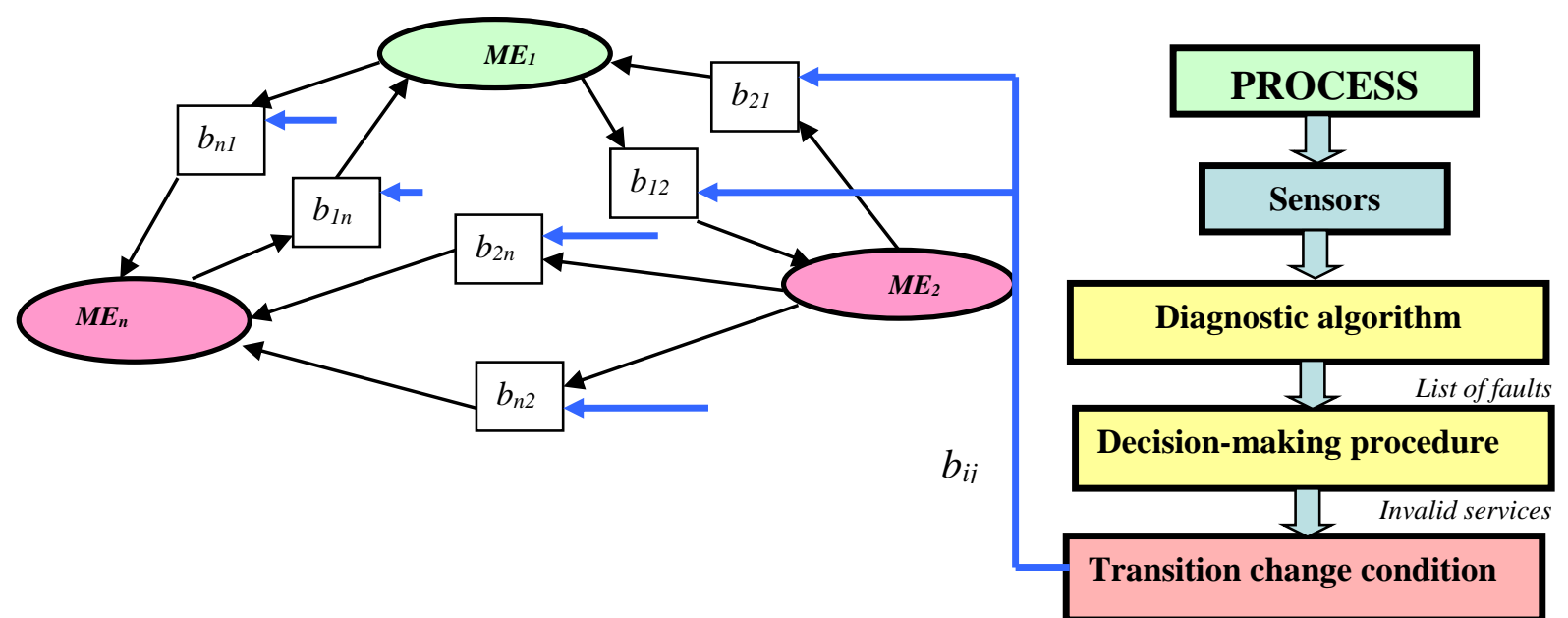

Figure.14. Supervision system integrating external models and the bond graph tool

\section{1. Concept of services and missions using bon graph}

In the sense of leap graphs, the services provided by the equipment of energy sources of the mechanical (motor), thermal (thermo resistance, potential energy or kinetic of a fluid) and hydraulic (pump) type energy sources are represented by sources of energy, Effort $S e(M S e)$ or flow $S f(M S f)$. The services provided by the functional role of the equipment (storing, transforming, transporting, etc.) are designated by the leaf graph elements $R, C, T F$ and $G Y$. The services offered by the sensors (measurements) are ensured by the force $(D e)$ and flow (Df) detectors, the requests associated with these services are modeled by information links.

It should be noted, however, that the leap graph services can be quantified by constitutive equations of the modeled leap graph elements. Missions represented by sets of the highest level services as defined in the external model must satisfy all the objectives set out in the specification and are of course based on the services offered by the lower level equipment.

\section{2. Concept of Operating Modes in Bond Graph}

At all times, an installation operates in an operating mode whose behavior is described by a Bond Graph model. Thus, each mode of operation (MEI) corresponds to a bond graph $M B G i$ model represented by figure 9 [46].

If $S i$ is the set of jump graph elements and $V i$ is the version of each set, then the jump graph model is the sum of these sets associated with the $M E_{i}$ mode, ie the following relation: $M B G i=M E i=\left\{S_{1}\left(V_{1}\right), S_{2}\left(V_{2}\right) \ldots, S_{n}\left(V_{n}\right)\right\}$.

The bond graph $M B G_{i}$ models of the system are linked by bij transitions, for each two jump graph models there are corresponding transition elements specific to them, for example in figure 15, the pattern graph respectively $M B G_{2}$ and $M B G_{n}$ are linked by the transition elements $b_{2 n}$ and $b_{n 2}$.

From the point of view of industrial process monitoring, the causal properties of the leap graph are used for the detection and isolation of faults affecting the sensors, actuators or physical components of the process. Thus, the availability of the services (necessary for the realization of a mission) will be provided by the monitoring algorithm to the graph of management of operating modes.

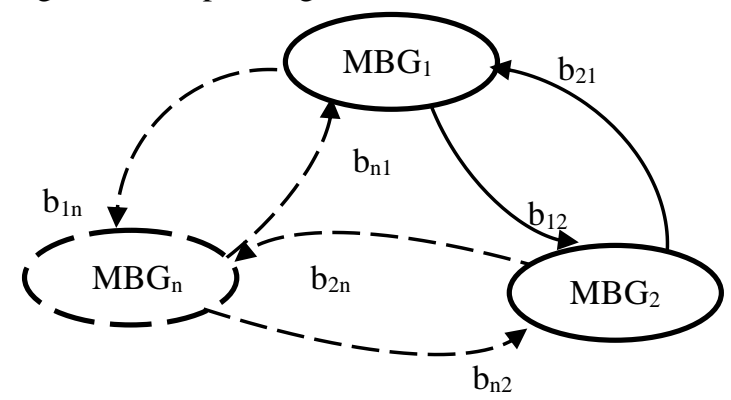

Figure.15. Management graph of the ME using BG 


\section{SUPERVISION OF THE DESALINATION UNIT BY EXTERNAL AND BOND GRAPH MODELS}

As we saw at the beginning, the desalination unit is composed of two reverse osmoses $\left(R O_{I}\right)$ and $\left(R O_{2}\right)$ placed in parallel with room temperature according to figure 16. Now we will give more detail for the desalination unit, the circulation of the liquid (salt water) is ensured by a pump through the valve $V_{l}$, the valve $V_{2}$ ensures the circulation of the liquid in both reverse osmoses $\left(R O_{1}\right)$ and $\left(R O_{2}\right)$. The adjustment of the reverse osmosis supply pressure $\left(R O_{l}\right)$ is carried out by the control valve $V_{4}\left(M R_{l}\right)$, located downstream of the reverse osmosis water discharge circuit $\left(R O_{1}\right)$. Also, the adjustment of the reverse osmosis supply pressure $\left(R O_{2}\right)$ is determined by the control valve $V_{5}\left(M R_{2}\right)$, located downstream of the reverse osmosis water discharge circuit $\left(\mathrm{RO}_{2}\right)$. When we want to have more quantity of water produced, we must operate with two reverse osmoses (normal operation). Reduced operation is ensured with a single reverse osmosis. After a complete shutdown (maintenance of the circuit, emptying ...), the restart will be possible only if the tank is empty.

\section{1. Services rendered}

The desalination unit consists of a set of equipment (tank, pump, two reverses osmosis...) which are organized in such a way that the system can meet the objectives for which it was designed. These devices are arranged in two ways:

- Low level: These are basic services; they are directly interfaced with the process (pumps, valves, sensors).

- High level: These are composed services; they are composed by basic services (feeding circuit, water circuit of rejection, circuit of the water produced ...).

According to this principle, it is possible to give a decomposition of the desalination system in figure 17.

\section{2. Missions}

The highest level services are referred to as missions. They must make it possible to satisfy all the objectives set out in the specifications. The various missions of the desalination unit are as follows:

- Mission 1: Put salted water in the tank;

- Mission 2: Check the performance of the devices.

- Mission 3: Set the bypass of the supply circuit (close valve $V_{2}$ and open valve $V_{l}$ ).

- Mission 4: Ensure filtration of salt water by two reverse osmoses.

- Mission 5: Ensure filtration of salt water by a single reverse osmosis.

- Mission 6: Stop the installation.

- Mission 7: Drain the circuits.

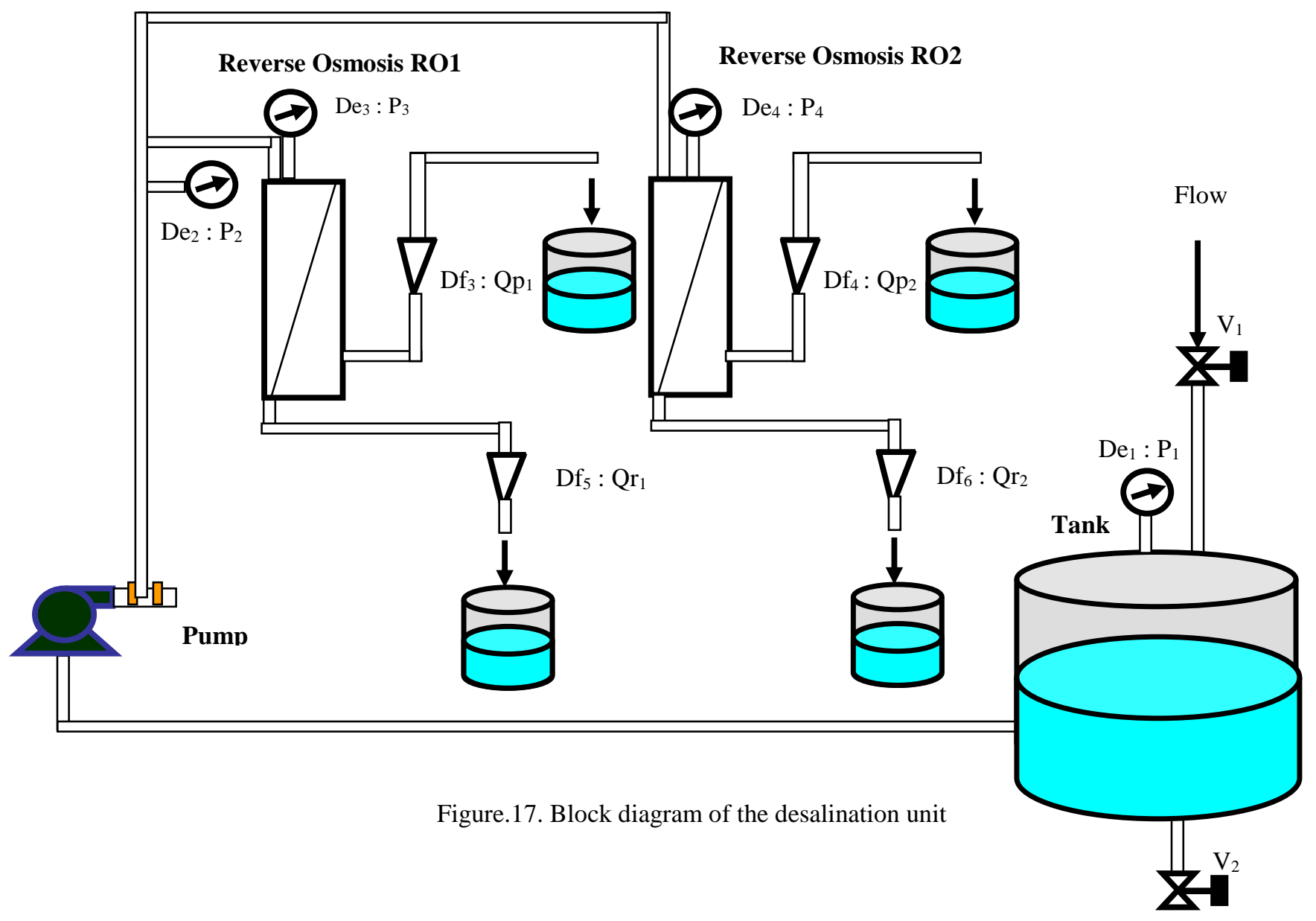


1: Salted water storage tank;

2: High pressure pump;

3: Reverse osmosis module power supply circuit with bypass and pressure measurement;

4: Reverse Osmosis $\mathrm{RO}_{1}$;

5: Reject water circuit with control valve and flow measurement $Q r_{i}$;

6: Circuit of the produced water and flow measurement $Q p_{1}$;

7: Reverse Osmosis $\mathrm{RO}_{2}$;

8: Reject water circuit with control valve and flow measurement $Q r_{2}$

9: Circuit of water produced $Q p_{2}$.

\section{3. Operating modes}

The missions of the desalination unit are those who are the first to manage and manage the system in accordance with the objectives of the specifications. But at a given moment, only a subset of these missions is necessary to meet the objectives set. Each of these subsets is referred to as the operating mode.

For this desalination system, four modes of operation figure 18 can be distinguished:

- Starting mode $\left(\mathrm{ME}_{1}\right)$ : The tank is full of salt water and the valve $V_{l}$ is open $(1,2,3)$.

- Normal mode of operation $\left(\mathrm{ME}_{2}\right)$ : Water filtering is ensured by two reverse osmoses (Missions: 1, 2, 3, 4, 6 and 7).

- Reduced operating mode $\left(\mathrm{ME}_{3}\right)$ : Water filtering is ensured by a single reverse osmosis (Missions: 1, 2, 3, 5, 6 and 7).

- Stopped mode (ME $\mathrm{ME}_{4}$ : The liquid circulation is stopped and the drain can be ensured (Missions: 6 and 7).

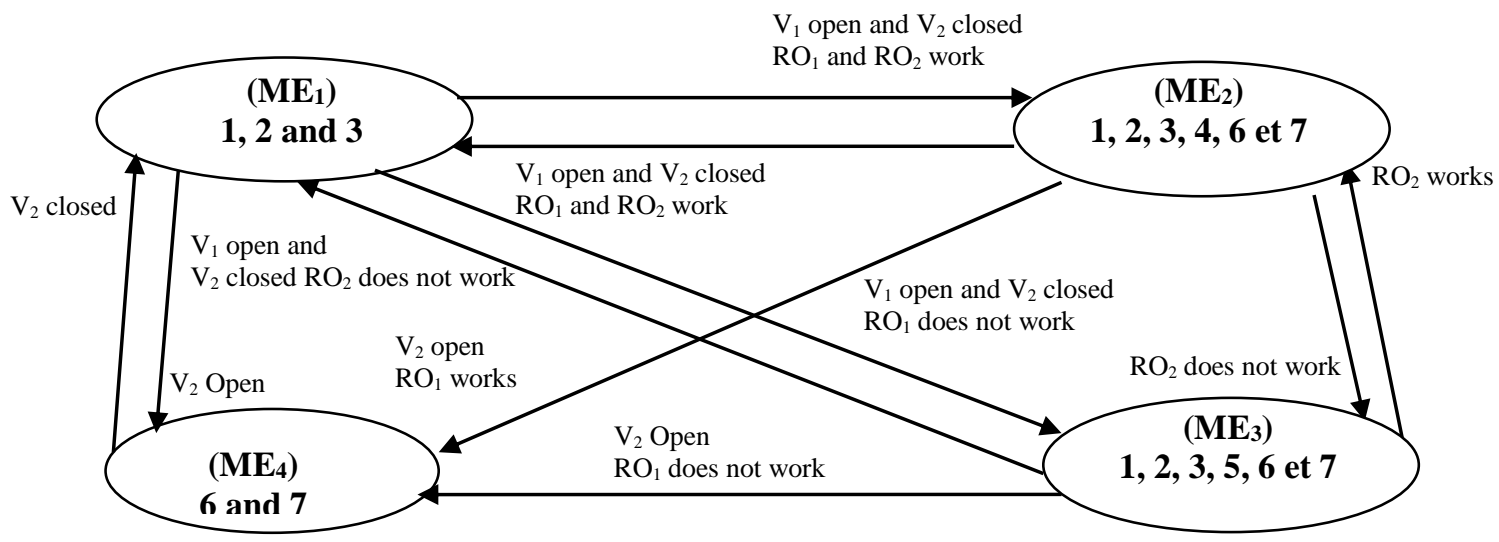

Figure.18. Graph of management of operating modes and associated missions

\section{4. Integration of external and bond graph models for the supervision of the desalination unit}

In the second chapter, we saw that a mode of exploitation of the external model (MEi) corresponds to a model graph graph that we denote $M B G i$. For the desalination unit, there are four modes of operation; each mode of operation $(M E i)$ corresponds to a leap graph $(M B G i)$ model:

1. Starting: $M E_{1}=M B G_{1}$

2. Normal operation: $M E_{2}=M B G_{2}$

3. Reduced operation: $M E_{3}=M B G_{3}$

4. Stop: $M E_{4}=M B G_{4}$

$\mathrm{V}_{1}, \mathrm{~V}_{2}$ open and $\mathrm{V}_{3}$ closed

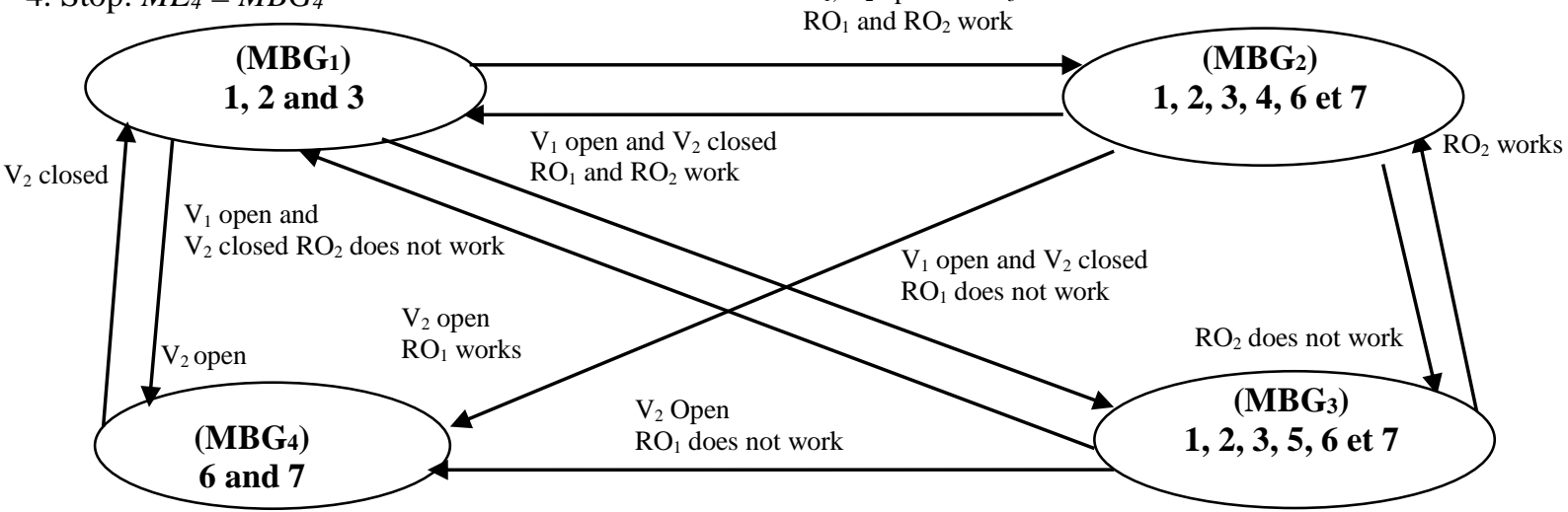

Figure.19. Graph of management of operating modes and associated missions 


\section{4. 1. Bond graph model of normal operation}

In this mode of operation $\left(M E_{2}\right)$, the desalination unit allows the filtering of salt water by two reverse osmoses. The pattern graph $\left(M B G_{2}\right)$ is given in figure 20; this model clearly shows the physical phenomena taking place there.

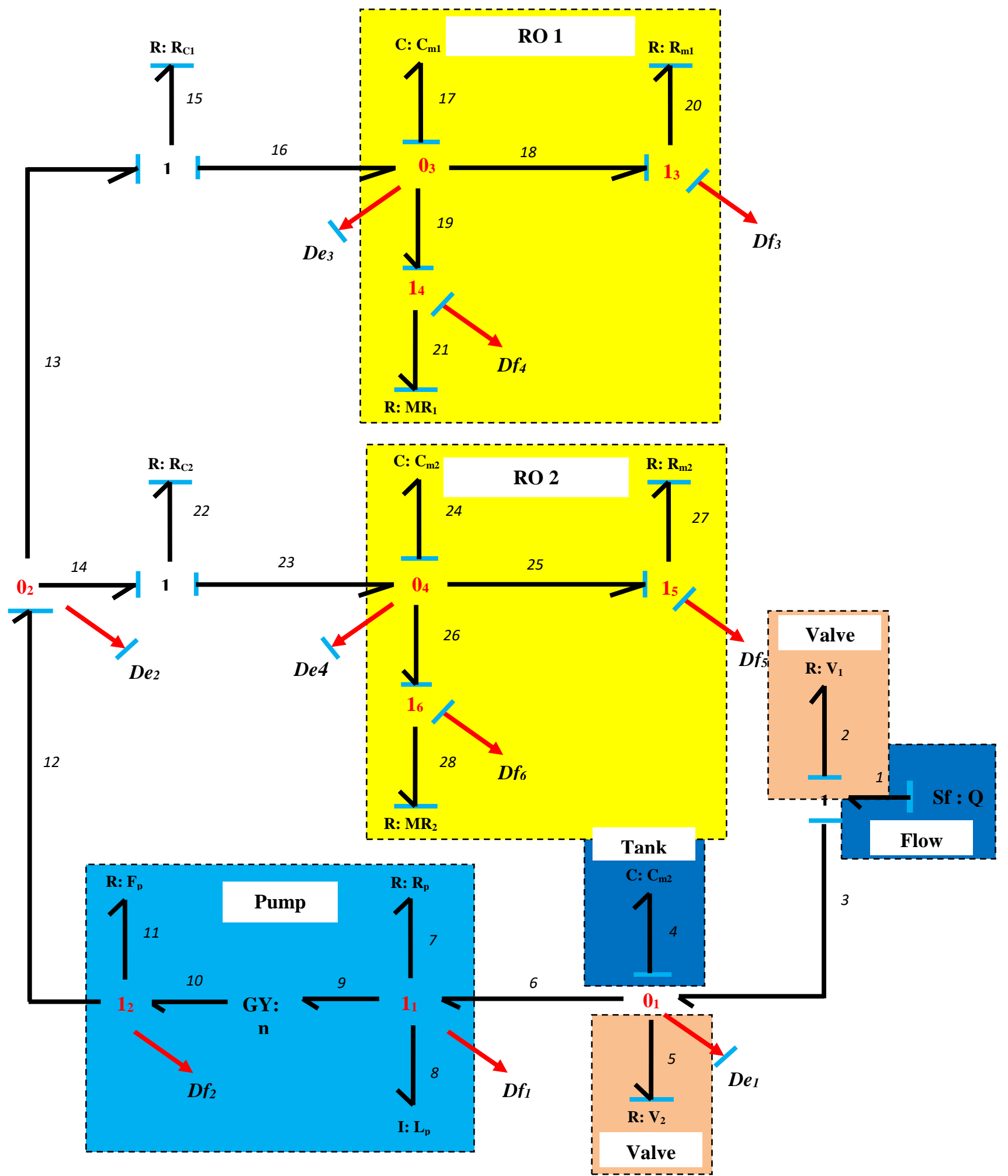

Figure.20. Bond graph of desalination unit for normal mode $\mathrm{MBG}_{2}$

\section{4. 2. Bond graph model of operating mode reduced operation}

In this mode of operation $\left(M E_{3}\right)$, the desalination unit allows the filtration of salt water by a single reverse osmosis. The bond graph model $\left(M B G_{3}\right)$ corresponding to this mode of operation $\left(M E_{3}\right)$ can easily be deduced 
from the bond graph model $\left(M B G_{2}\right)$ by removing a reverse osmosis (under system 2), then the bond graph model given by the figure 21 .

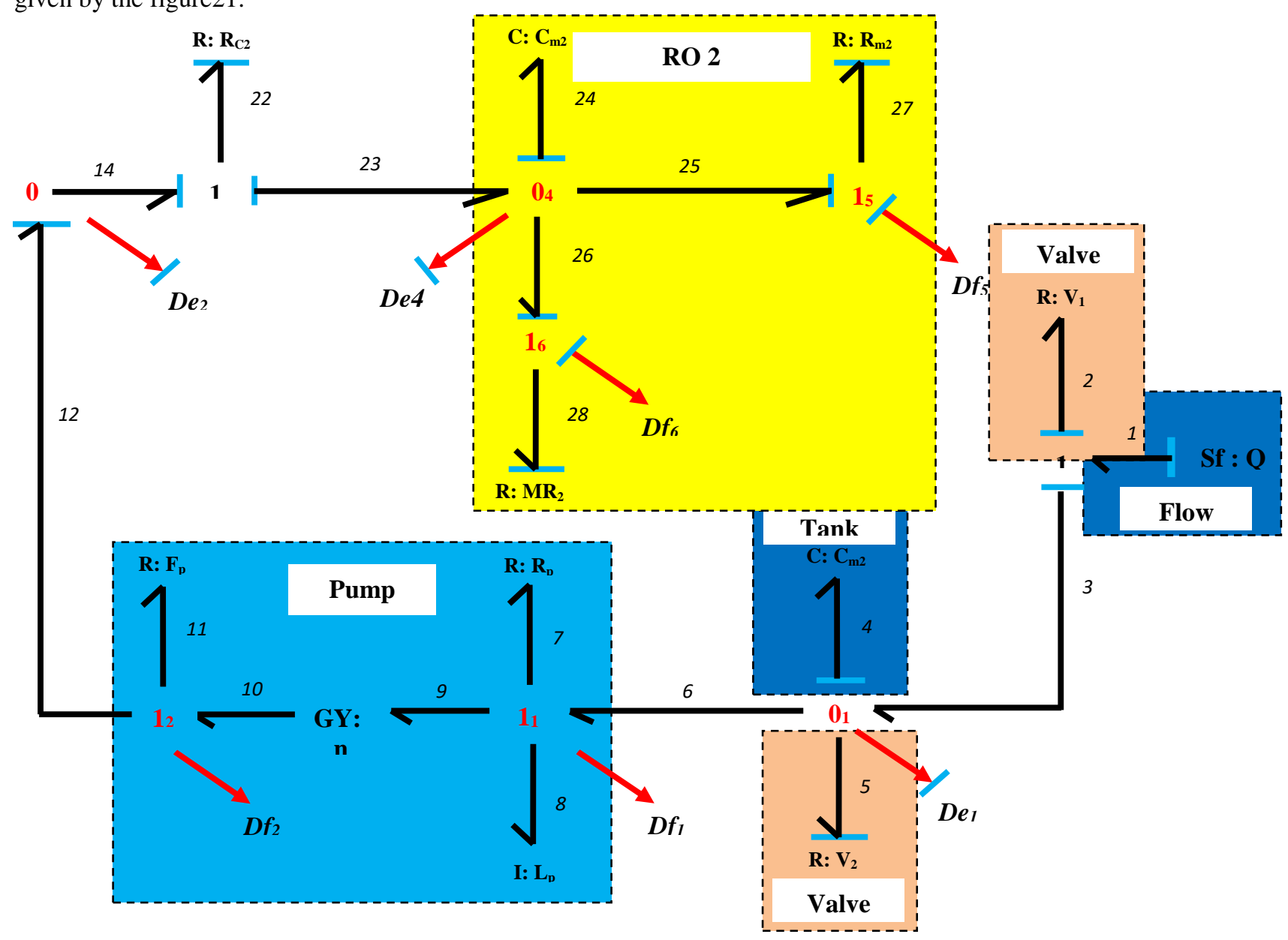

Figure.21. Bond graph model $\left(M B G_{3}\right)$ of the desalination unit for reduced mode

\section{4. 3. Bond graph model in stop mode}

In this mode, the circulation of the liquid is stopped and the emptying can be ensured by the valve $V_{3}$. The bond graph model $\left(M B G_{4}\right)$ corresponding to this mode of operation $M E_{4}$ is given in figure 22.

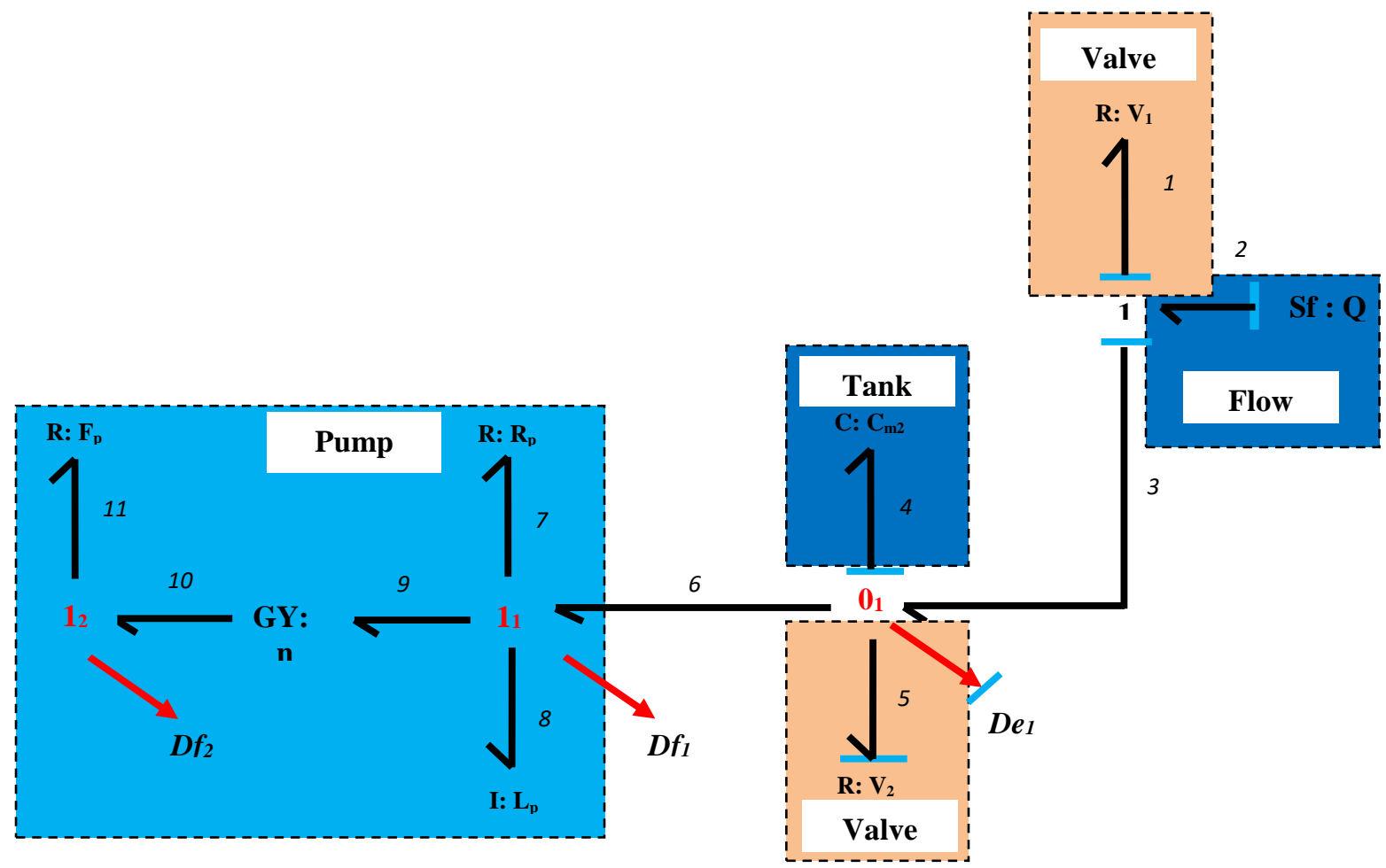

Figure.22. Bond graph model of the desalination unit for the stop mode $\left(M B G_{4}\right)$ 


\section{5. Reconfiguration of desalination unit by external models and bond graphs}

\section{5. 1. Reconfiguration of desalination unit by external model}

In the event of material failures, the desalination system becomes incapable of carrying out part of its missions for which it was designed. Driving and maintenance operators must be informed. For (04) alarms were associated with the desalination system and are illustrated in table 1 this table gives for each defect a list of services and missions.

Table.4. Consequences of defects on the availability of services and missions

\begin{tabular}{|c|l|l|l|l|}
\hline Alarm & \multicolumn{1}{|c|}{ Defaults } & \multicolumn{1}{|c|}{ Low level service } & High level Service & \multicolumn{1}{c|}{ Missions } \\
\hline 01 & $V_{l}$ valve blocked & Supply valve & Pumping unit & 1,2 and 3 \\
\hline 02 & Membrane clogging $\left(R O_{1}\right)$ & Reverse Osmosis $\left(R O_{1}\right)$ & Filter unit 1 & $1,2,3,4$ and 5 \\
\cline { 2 - 5 } & Leakage $\left(R O_{1}\right)$ & Filter unit 2 & \multirow{2}{*}{$1,2,3$ and 4} \\
\hline 03 & Membrane clogging $\left(R O_{2}\right)$ & \multirow{2}{*}{ Reverse Osmosis $\left(R O_{2}\right)$} & & 1,2 and 3 \\
\cline { 2 - 5 } & Leakage $\left(R O_{2}\right)$ & Pump & Pumping unit & \\
\hline
\end{tabular}

From the external model point of view, alarm $(02)$ is a fault associated with reverse osmosis $\left(R O_{l}\right)$, so the affected missions are: 1, 2, 3, 4 and 5 .

- Mission 1, Mission 2 and Mission 3: We find these missions in the startup mode; the absence of these missions makes the startup mode unavailable. If the start mode is the current mode, in the presence of a fault, the automatic switch-over is to stop mode.

- Mission 4: We find this mission in the operating mode in normal operation. In the event of a fault, the operating mode in normal operation is not available (since the service rendered for this element exists in this mode), the transition to the stop mode is allowed.

- Mission 5: We find this mission in the operating mode in reduced operation. In the event of a fault, the operating mode in reduced operation is not available (since the service rendered for this element exists in this mode), the transition to the stop mode is envisaged.

\section{5. 2. Reconfiguration of desalination unit by bond graph model}

The alarm (02) corresponds to a fault (leakage) at the level of the reverse osmosis $\left(R O_{I}\right)$, this fault causes a reduction in the quantity of water for the two circuits (water circuit produced and circuit water discharge). These phenomena are readable on the bond graph model and can be quantified by the equations. However, this failing component $\left(R O_{1}\right)$ is in the normal modes $M E_{2}\left(M B G_{2}\right)$ and reduces $M E_{3}\left(M B G_{3}\right)$, so that switching to the $M E_{4}$ mode is allowed. For the generation of the residuals of each mode, we applied the ARRs method. In the case of the normal mode $M E_{2}\left(M B G_{2}\right)$ we arrive at the equations of the following residuals:

\section{Pumpin system}

- Residue $r_{l}$ :

$$
r_{l}=Q-\frac{D e_{1}}{V_{2}}-C_{u} \cdot \frac{d D e_{1}}{d t}-D f_{l}
$$

- Residue $r_{2}$ :

$$
r_{2}=D e_{1}-V_{2} \cdot D f_{1}-R_{p} \cdot D f_{1}-L_{p} \cdot \frac{d D f_{1}}{d t}-n \cdot D f_{2}
$$

- Residue $r_{3}$ :

$$
r_{3}=n . . D f_{1}-f_{p} . D f_{1}-D e_{2}
$$

- Residue $r_{4}$ :

$$
r_{4}=D f_{2}-\frac{D e_{2}-D e_{3}}{R_{C 1}}-\frac{D e_{2}-D e_{4}}{R_{C 2}}
$$




\section{Reverse osmosis system $\left(\mathrm{RO}_{1}\right)$}

- Residue $r_{5}$ :

$$
r_{5}=\frac{D e_{2}-D e_{3}}{R_{C 1}}-C_{m l} \cdot \frac{d D e_{3}}{d t}-D f_{3}-D f_{4}
$$

- Residue $r_{6}$ :

$$
r_{6}=D e_{3}-R_{m 1} \cdot D f_{3}-C_{p 1} \cdot \int D f_{3}
$$

- Residue $r_{7}$ :

$$
r_{7}=D e_{3}-M R_{1} \cdot D f_{4}-C_{r 1} \cdot \int D f_{4}
$$

\section{Reverse osmosis system $\left(\mathrm{RO}_{2}\right)$}

- Residue $r_{8}$ :

$$
r_{8}=\frac{D e_{2}-D e_{4}}{R_{C 2}}-C_{m 2} \cdot \frac{d D e_{4}}{d t}-D f_{5}-D f_{6}
$$

- Residue $r_{9}$ :

$$
r_{9}=D e_{4}-R_{m 2} \cdot D f_{4}-C_{p 2} \cdot \int D f_{4}
$$

- Residue $r_{10}$ :

$$
r_{10}=D e_{4}-M R_{2} \cdot D f_{6}-C_{r 2} \cdot \int D f_{6}
$$

\begin{tabular}{|c|c|c|c|c|c|c|c|c|c|c|}
\hline & $r_{1}$ & $r_{2}$ & $r_{3}$ & $r_{4}$ & $r_{5}$ & $r_{6}$ & $\boldsymbol{r}_{7}$ & $r_{8}$ & $r 9$ & $r_{10}$ \\
\hline $\mathbf{Q}$ & 1 & 0 & 0 & 0 & 0 & 0 & 0 & 0 & 0 & 0 \\
\hline$V_{1}$ & 0 & 0 & 0 & 0 & 0 & 0 & 0 & 0 & 0 & 0 \\
\hline$V_{2}$ & 1 & 1 & 0 & 0 & 0 & 0 & 0 & 0 & 0 & 0 \\
\hline $\mathrm{C}_{\mathrm{u}}$ & 1 & 0 & 0 & 0 & 0 & 0 & 0 & 0 & 0 & 0 \\
\hline $\mathbf{R}_{\mathbf{p}}$ & 0 & 1 & 0 & 0 & 0 & 0 & 0 & 0 & 0 & 0 \\
\hline $\mathbf{L}_{\mathbf{p}}$ & 0 & 1 & 0 & 0 & 0 & 0 & 0 & 0 & 0 & 0 \\
\hline $\mathbf{n}$ & 0 & 1 & 1 & 0 & 0 & 0 & 0 & 0 & 0 & 0 \\
\hline $\mathbf{R}_{\mathrm{m} 1}$ & 0 & 0 & 0 & 0 & 0 & 1 & 0 & 0 & 0 & 0 \\
\hline $\mathrm{C}_{\mathrm{m} 1}$ & 0 & 0 & 0 & 0 & 1 & 0 & 0 & 0 & 0 & 0 \\
\hline $\mathrm{MR}_{1}$ & 0 & 0 & 0 & 0 & 0 & 0 & 1 & 0 & 0 & 0 \\
\hline $\mathbf{R}_{\mathbf{C} 1}$ & 0 & 0 & 0 & 1 & 1 & 0 & 0 & 0 & 0 & 0 \\
\hline
\end{tabular}

All residues are grouped in table 5. We get a boolean matrix; the columns are associated with the residues and the lines are the boolean signatures of the components to be monitored. The rows in the table below show the sensitivity of the residue to defects in the process components to be monitored.

Table 5: Signature of the defaults of the desalination system 


\begin{tabular}{|c|c|c|c|c|c|c|c|c|c|c|}
\hline $\mathbf{R}_{\mathbf{m} 2}$ & 0 & 0 & 0 & 0 & 0 & 0 & 0 & 0 & 0 & 0 \\
\hline $\mathrm{C}_{\mathrm{m} 2}$ & 0 & 0 & 0 & 0 & 0 & 0 & 0 & 1 & 0 & 0 \\
\hline $\mathbf{M R}_{2}$ & 0 & 0 & 0 & 0 & 0 & 0 & 0 & 0 & 0 & 1 \\
\hline $\mathbf{R}_{\mathbf{C} 2}$ & 0 & 0 & 0 & 1 & 0 & 0 & 0 & 1 & 0 & 0 \\
\hline De1 & 1 & 1 & 0 & 0 & 0 & 0 & 0 & 0 & 0 & 0 \\
\hline $\mathrm{De}_{2}$ & 0 & 0 & 1 & 1 & 1 & 0 & 0 & 0 & 0 & 0 \\
\hline $\mathrm{De}_{3}$ & 0 & 0 & 0 & 1 & 1 & 1 & 1 & 1 & 0 & 0 \\
\hline $\mathbf{D e}_{4}$ & 0 & 0 & 0 & 1 & 0 & 0 & 0 & 1 & 1 & 1 \\
\hline Df $_{1}$ & 1 & 1 & 1 & 0 & 0 & 0 & 0 & 0 & 0 & 0 \\
\hline Df $_{2}$ & 0 & 1 & 0 & 1 & 0 & 0 & 0 & 0 & 0 & 0 \\
\hline $\mathrm{Df}_{3}$ & 0 & 0 & 0 & 0 & 1 & 1 & 0 & 0 & 0 & 0 \\
\hline $\mathrm{Df}_{4}$ & 0 & 0 & 0 & 0 & 1 & 0 & 1 & 0 & 1 & 0 \\
\hline Df $_{5}$ & 0 & 0 & 0 & 0 & 0 & 0 & 0 & 1 & 0 & 0 \\
\hline Df $_{6}$ & 0 & 0 & 0 & 0 & 0 & 0 & 0 & 1 & 0 & 1 \\
\hline
\end{tabular}

We can see from this table that the components $\left(V_{2}, R_{C 1}, R_{C 2}, D_{e 1}, D_{e 2}, D_{e 3}, D e 4, D f_{1}, D f_{2}, D f_{3}, D f_{4}, D f_{5}\right.$ and $D f_{6}$ ) have the same signature for several residues and consequently a fault in the valve (valve clogged) and a fault in the sensors (leakage or deformation) are not isolable. To solve this monitoring problem a linear combination between the residual equations allows to eliminate certain variables redendente is necessary.

On the other hand, a defect in the tank $(\mathrm{Cu})$ or reverse osmosis $\left(R O_{1}\right.$ and $\left.R O_{2}\right)$, leakage or deformation, are usable.

From bond graph model shown in figure 20, we added the model of the equations of residues $r_{1}, r_{2}, r_{3}, r_{4}, r_{5}, r_{6}$, $r_{7}, r_{8}, r_{9}$ and $r_{10}$ at each junction 0 or 1 , using the software 20-sim41, as shown in figure 23 . The pressures and flow rates for each reverse osmosis are measured respectively by effort sensors for pressures $\left(D e_{3}\right.$ or $R O_{1}$ and $D e_{4}$ for $\left.R O_{2}\right)$ and flow detectors for flow rates $\left(D f_{3}\right.$ and $D f_{4}$ for reverse osmosis $R O_{1}, D f_{5}$ and $D f_{6}$ for reverse osmosis $\mathrm{RO}_{2}$ ). The pressures at the $\mathrm{Cu}$ reservoir level and at the inlet of the two reverse osmosis are measured by effort sensors $D e_{1}$ and $D e_{2}$. The current and speed at the pump levels are measured by flow detectors respectively $D f_{1}$ and $D f_{2}$. 


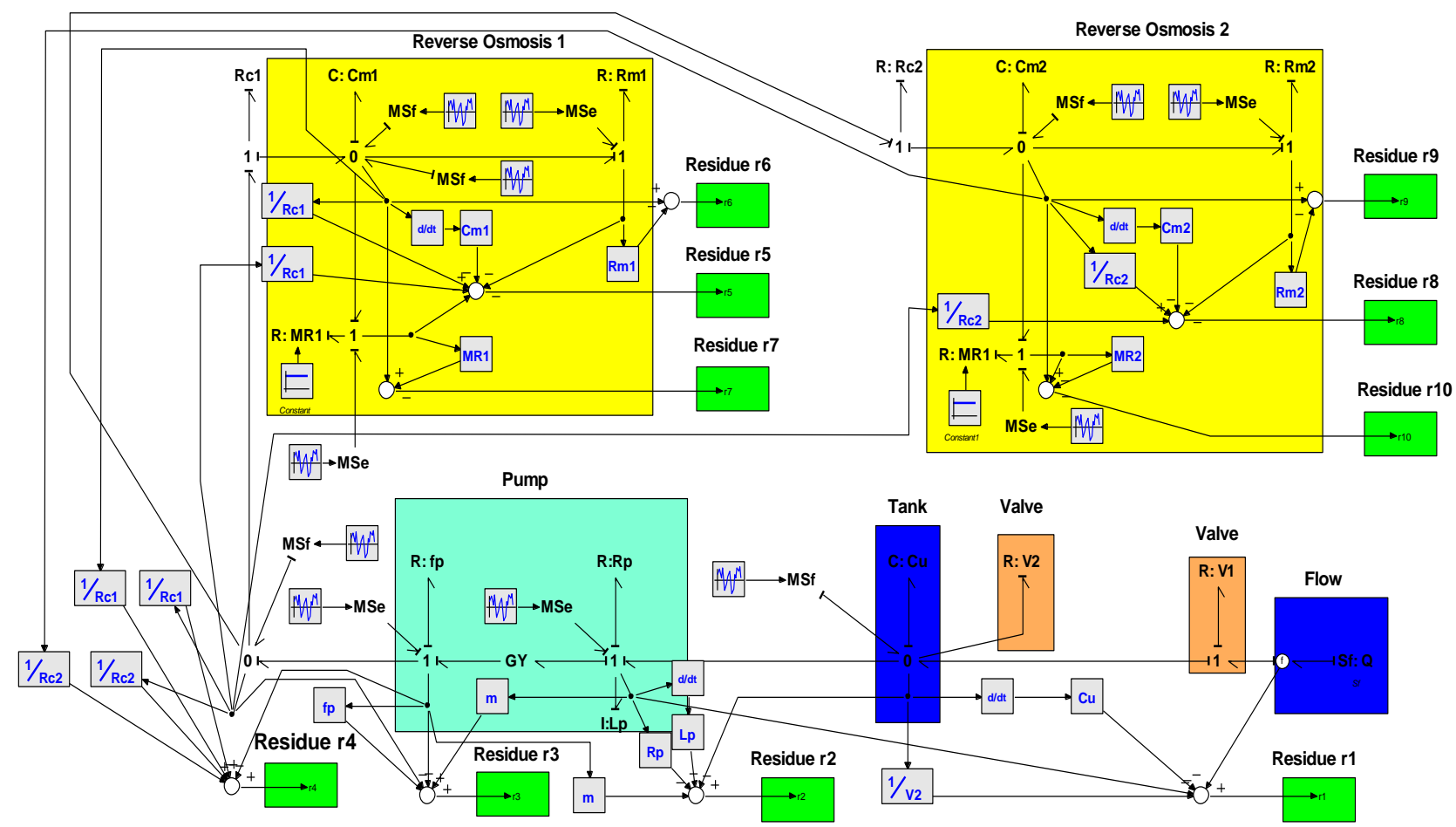

Figure23. Complete BG model used for the measures of the variables and the fault diagnosis

The simulation of the BG model presented in figure 23 was carried out by software 20SIM-41. The curves of the pressures $\left(P_{1}\right.$ and $\left.P_{2}\right)$ and the flow rates $\left(Q p_{1}, Q r_{1}, Q p_{2}\right.$ and $\left.Q r_{2}\right)$ respectively for the two reverse osmosis are determined in figures 24 and 25 . The pressures reach $3000 \mathrm{~Pa}$ and the flow rates $Q p_{1}=Q p_{2}=2 * 10^{-4} \mathrm{~m}^{3} / \mathrm{s}$ and $Q r_{1}=Q r_{2}=2 * 10^{-2} \mathrm{~m}^{3} / \mathrm{s}$.

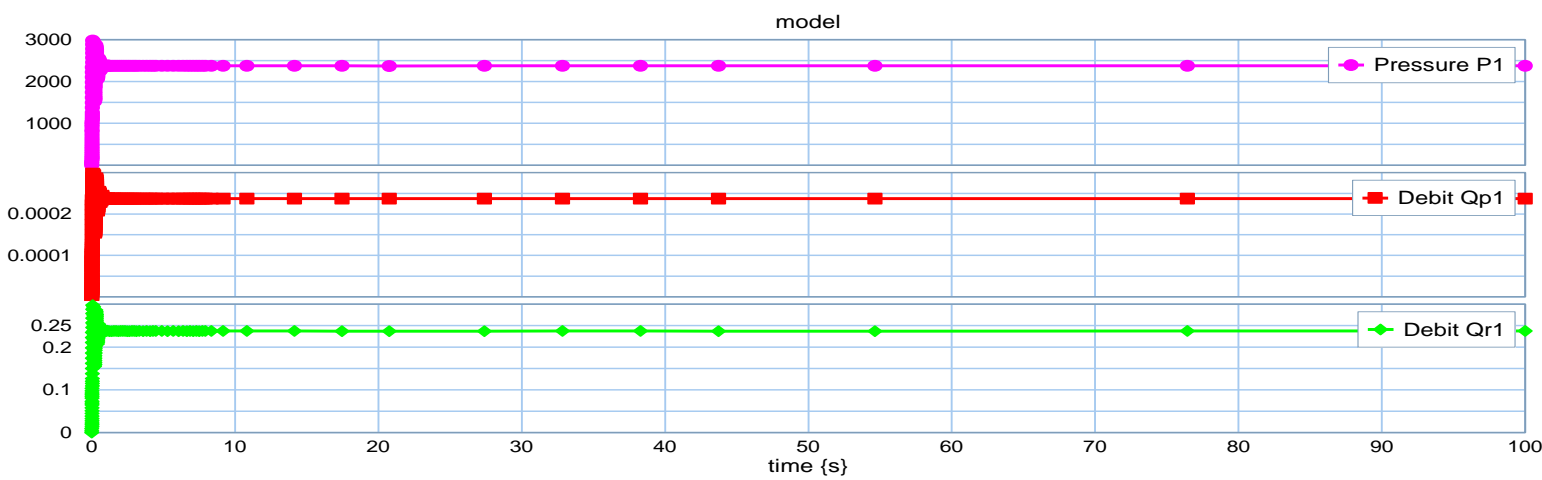

Figure24. Variation of Pressure $\left(P_{l}\right)$ and flow rates $\left(Q p_{1}\right.$ and $\left.Q r_{l}\right)$ as a function of time for $R O_{l}$

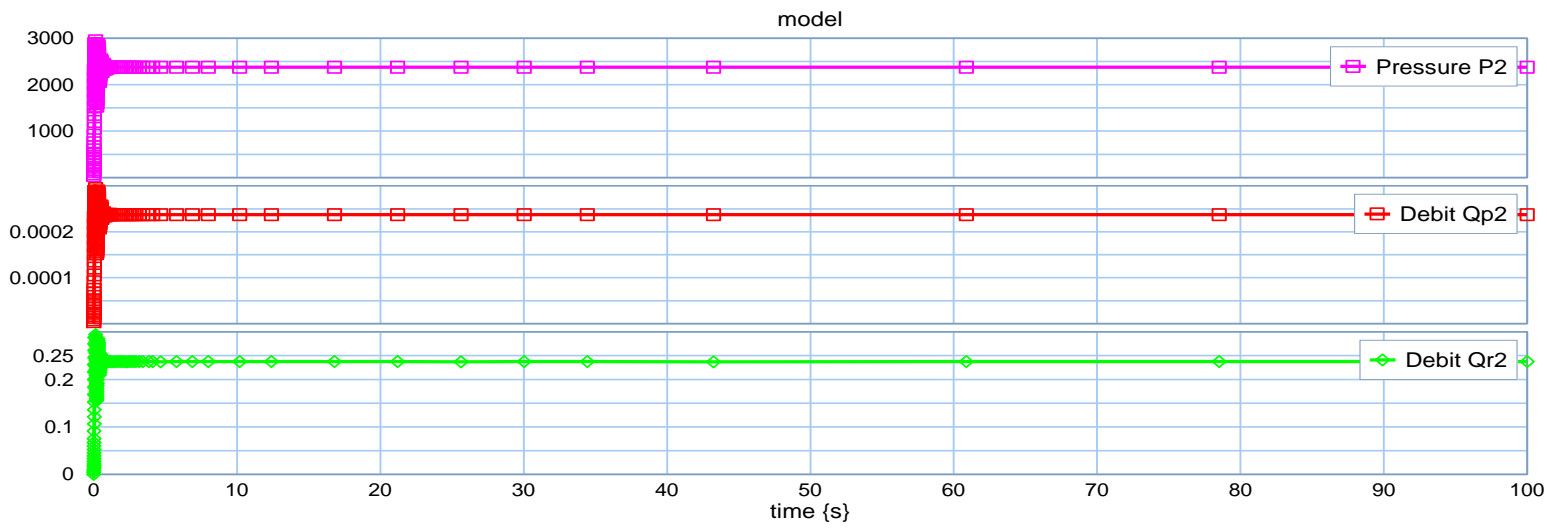

Figure.25. Variation of Pressure $\left(P_{2}\right)$ and flow rates $\left(Q p_{2}\right.$ and $\left.Q r_{2}\right)$ as a function of time for $\mathrm{RO}_{2}$ 
Figure 26 shows the patterns of residues $\left(r_{5}, r_{6}\right.$ and $\left.r_{7}\right)$ in reduced operation mode $\left(M E_{3}\right)$. In the case of a reverse osmosis $\left(R O_{l}\right)$ fault, the residuals become non-zero figure 27. Indeed, the equation of the model of this reverse osmosis $\left(R O_{1}\right)$ is found in the residue equations $\left(r_{5}, r_{6}\right.$ and $\left.r_{7}\right)$, so these residues will be sensitive to this default.

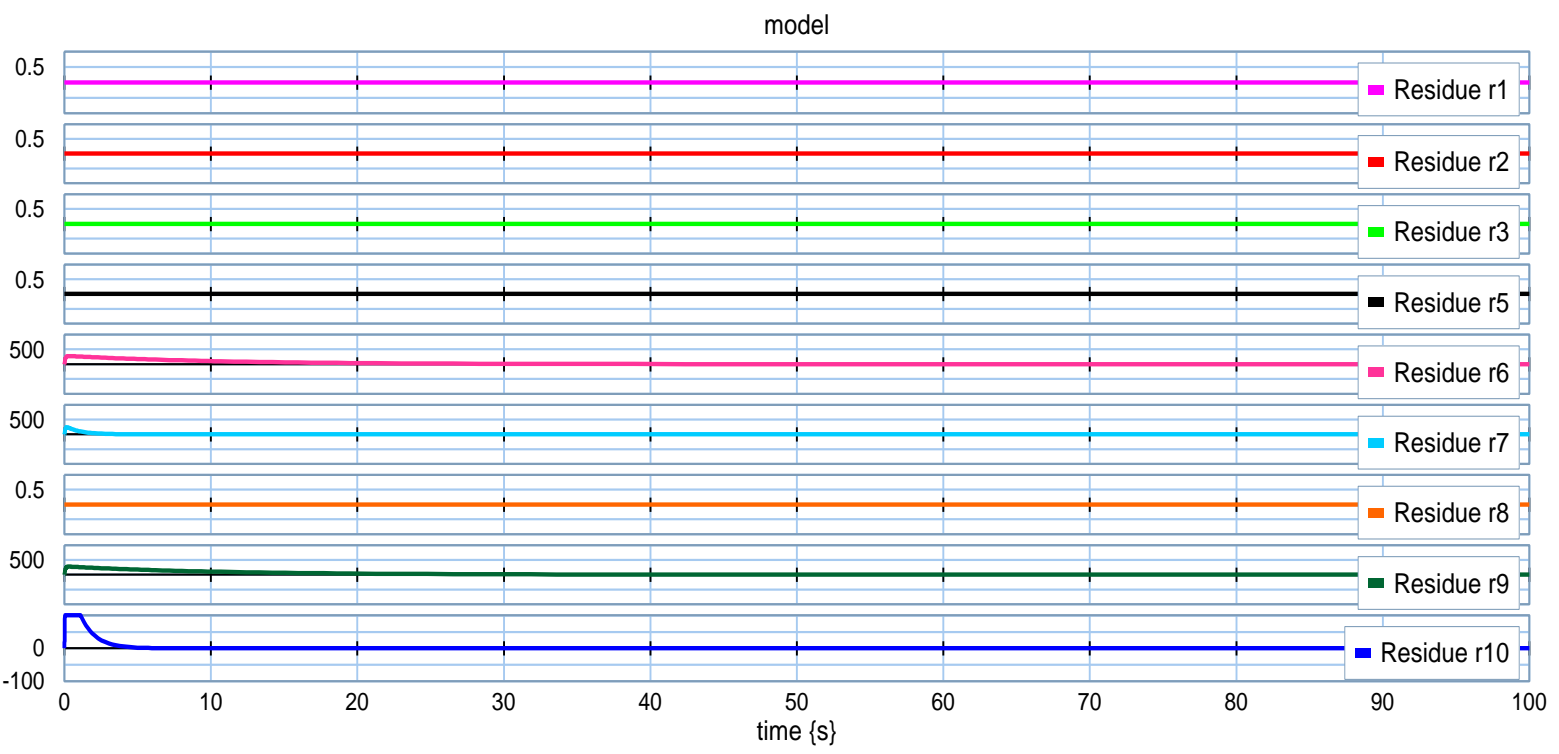

Figure.26. Evolution of the residues without defaults

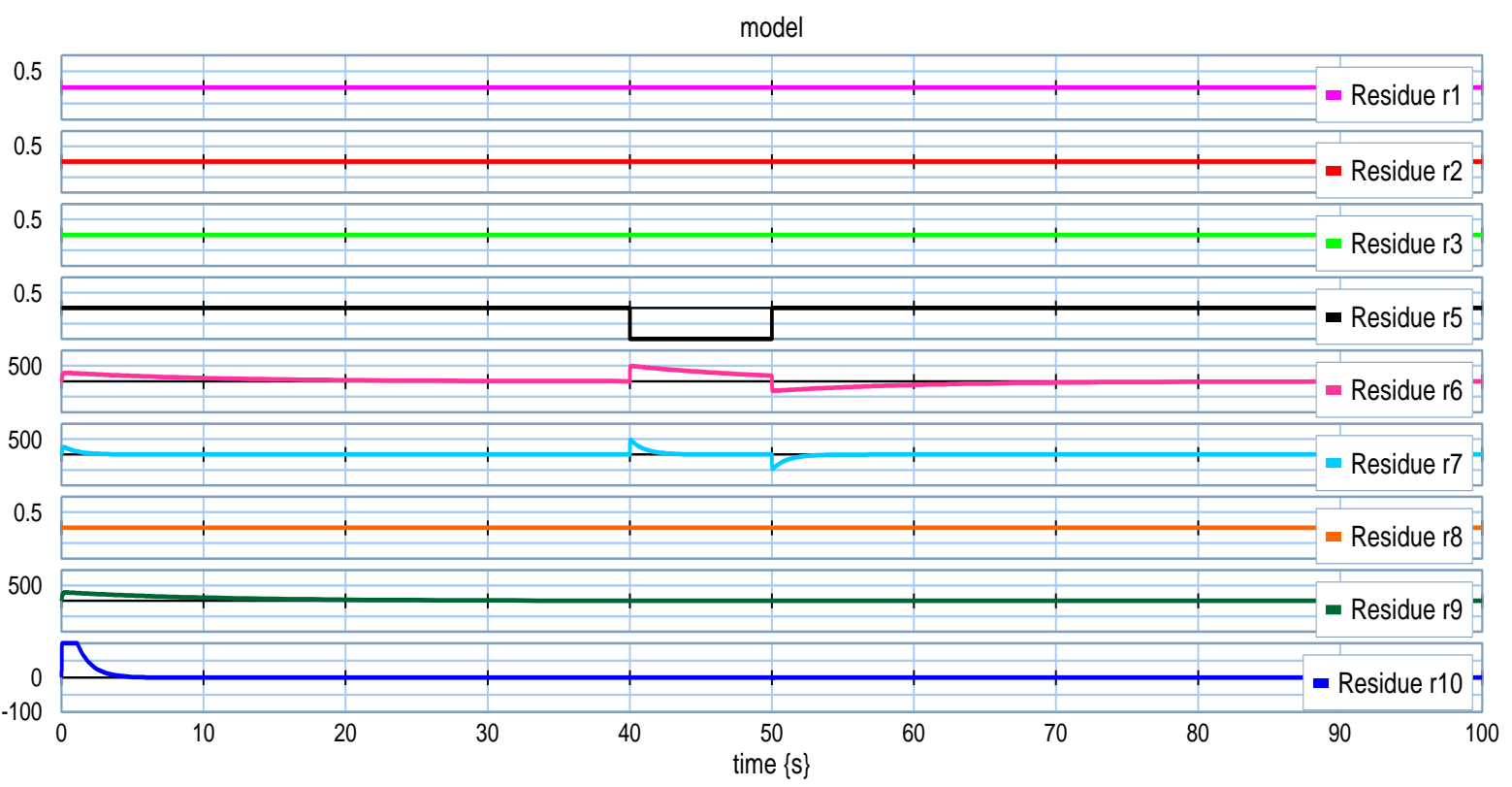

Figure.27. Evolution of residues with defaults in $\left(R O_{1}\right)$

\subsection{Robust supervision by bond graphs the desalination system}

For our desalination system the BG-LFT model in integral causality is given by figure 28 .

To determine the equations of the residues must be given the BG-LFT model desalination system in derived causality that shown in figure 29 . 


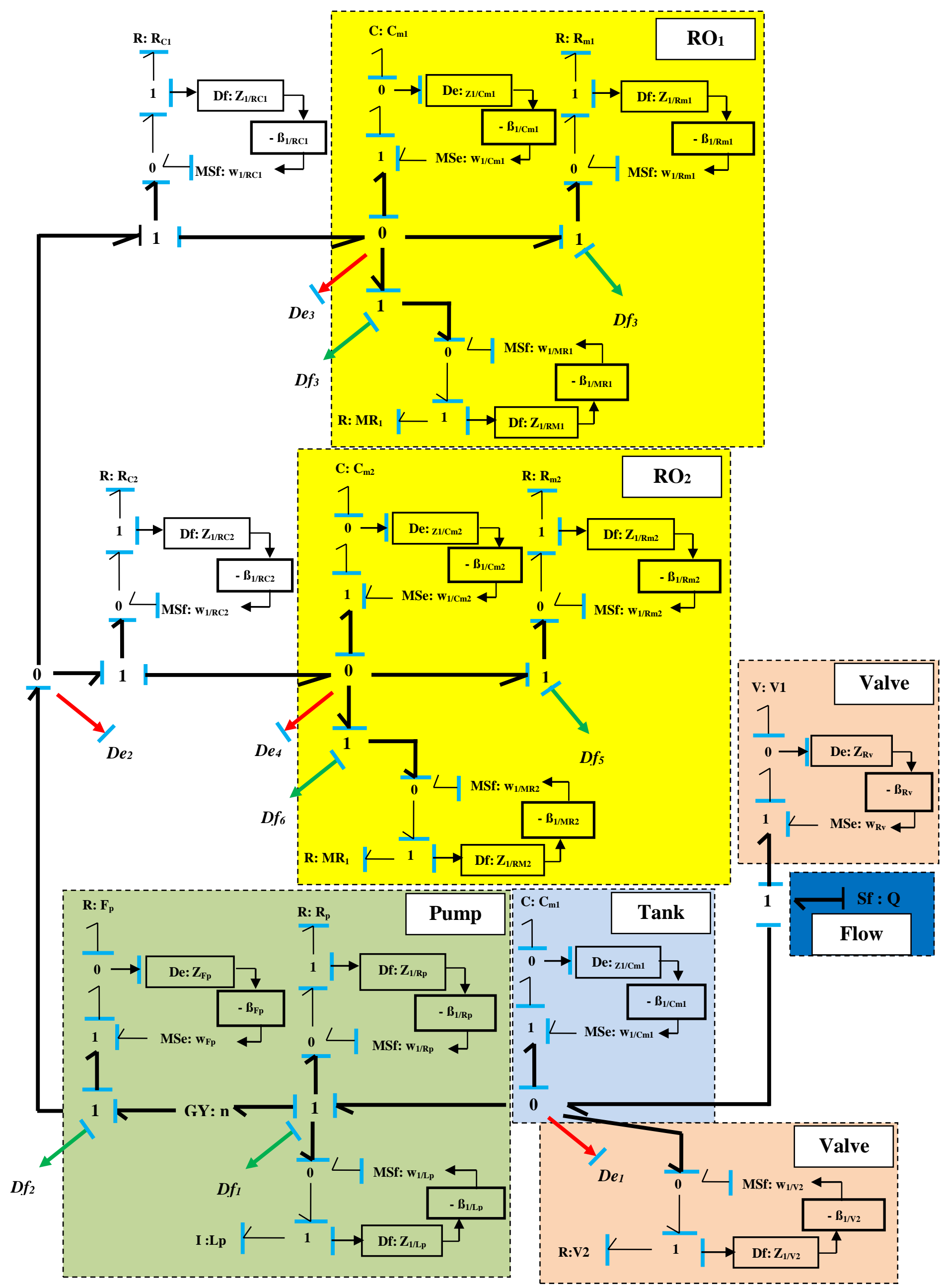

Figure.28. BG-LFT model of the desalination system in integral causality 


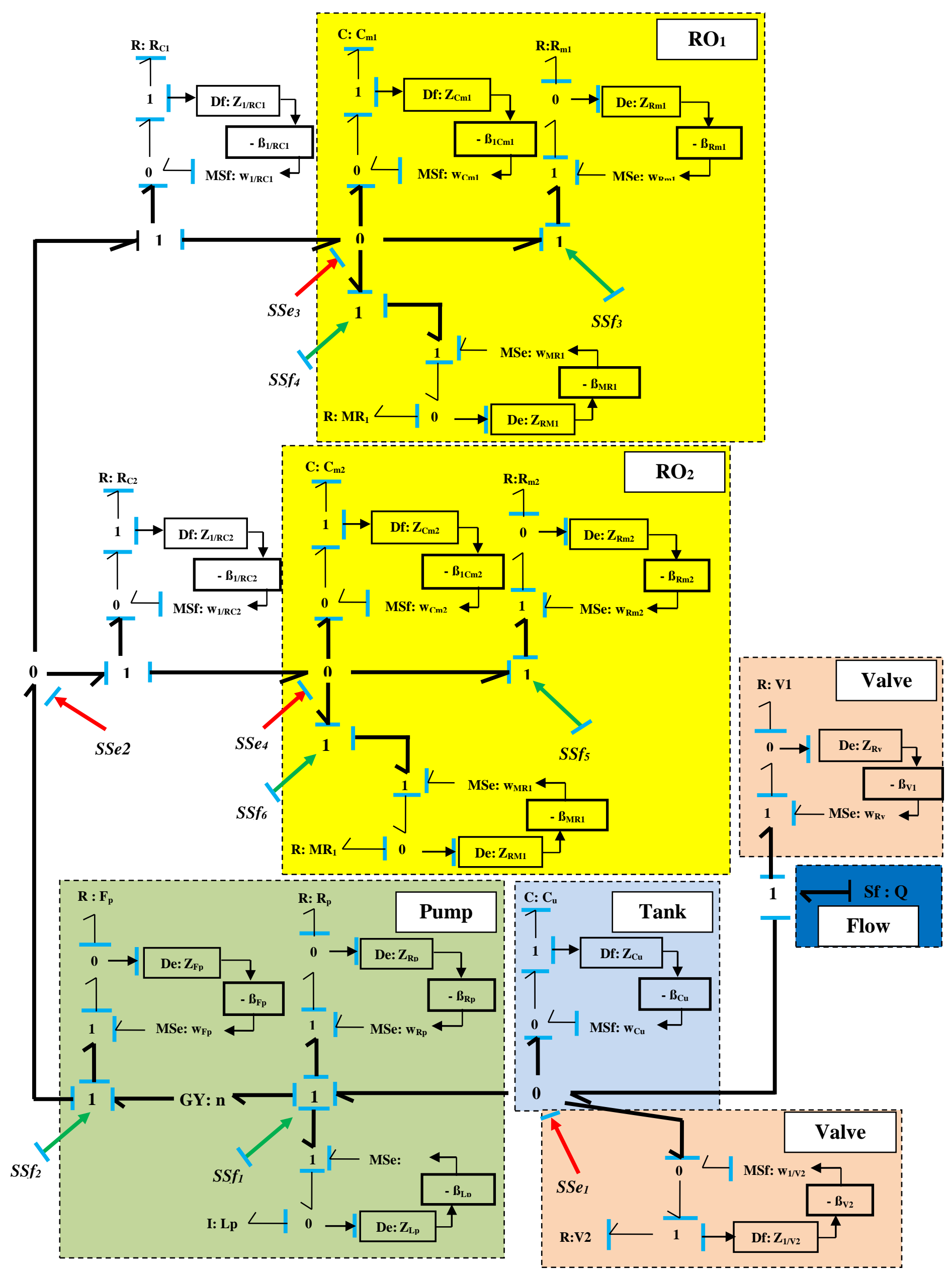

Figure.29. BG-LFT model of the desalination system in derived causality without faults 
Determination of uncertain residues by the BG-LFT model without faults:

$\checkmark$ Pumping system :

$>$ Residue $R_{d l}: \quad R_{d 1}(t)=Q-\frac{D e_{1}}{V}-C_{u} \cdot \frac{d D e_{1}}{d t}-D f_{1}+w_{V 2}+w_{C u}$

$$
\left\{\begin{array}{l}
R_{d 1}(t)=r_{1 n}(t)+d_{1} \\
r_{l n}(t)=Q-\frac{D e_{1}}{V}-C_{u} \cdot \frac{d D e_{1}}{d t}-D f_{1} \\
d_{1}=w_{V 2}+w_{C u}
\end{array}\right.
$$

Residue $R_{d 2}: \quad R_{d 2}(t)=D e_{1}-\frac{D e_{1}}{R_{p}}-L_{P} \cdot \frac{d D f_{1}}{d t}-m \cdot D f_{2}+w_{R P}+w_{L p}$

$$
\left\{\begin{array}{l}
R_{d 2}(t)=r_{2 n}(t)+d_{2} \\
r_{2 n}(t)=D e_{1}-\frac{D e_{1}}{R_{p}}-L_{P} \cdot \frac{d D f_{1}}{d t}-m \cdot D f_{2} \\
d_{2}=w_{R P}+w_{L p}
\end{array}\right.
$$

Residue $R_{d 3}: \quad R_{d 3}=m \cdot D f_{1}-D e_{1}-f_{p} D f_{1}+w_{f p}$

$$
\left\{\begin{array}{l}
R_{d 3}=r_{3 n}(t)+d_{4} \\
r_{3 n}(t)=m \cdot D f_{1}-D e_{1}-f_{p} D f_{1} \\
d_{3}=w_{f p}
\end{array}\right.
$$

Residue $R_{d 4}: R_{d 4}(t)=D f_{2}-\frac{D e_{2}-D e_{1}}{R_{C 1}}-\frac{D e_{2}-D e_{4}}{R_{C 2}}+w_{R C 1}+w_{R C 2}$

$$
\left\{\begin{array}{l}
R_{4}(t)=r_{4 n}(t)+d_{4} \\
r_{4}(t)=D f_{2}-\frac{D e_{2}-D e_{1}}{R_{C 1}}-\frac{D e_{2}-D e_{4}}{R_{C 2}} \\
d_{4}=w_{R C 1}+w_{R C 2}
\end{array}\right.
$$

Residue $R_{d 5}: \quad R_{d 5}(t)=\frac{D e_{2}-D e_{1}}{R_{C 1}}-C_{m 1} \frac{d D e_{3}}{d t}-D f_{3}-D f_{4}+w_{R C 1}+w_{C m 1}$

$$
\left\{\begin{array}{l}
R_{d 5}(t)=r_{5}(t)+d_{5} \\
r_{5 n}(t)=\frac{D e_{2}-D e_{1}}{R_{C 1}}-C_{m l} \frac{d D e_{3}}{d t}-D f_{3}-D f_{4} \\
d_{5}+w_{R C 1}+w_{C m l}
\end{array}\right.
$$


Residue $R_{d 6}: \quad R_{d 6}(t)=D e_{3}-R_{m l} D f_{3}+w_{R m 1}$

$$
\left\{\begin{array}{l}
R_{d 6}(t)=r_{6 n}(t)+d_{6} \\
r_{6 n}(t)=D e_{3}-R_{m l} D f_{3} \\
d_{6}=w_{R m 1}
\end{array}\right.
$$

Residue $R_{d 7}: \quad R_{d 7}(t)=D e_{3}-M R_{1} D f_{4}+w_{M R I}$

$$
\left\{\begin{array}{l}
R_{d 7}(t)=r_{7 n}(t)+d_{7} \\
r_{7 n}(t)=D e_{3}-M R_{1} D f_{4} \\
d_{7}=w_{M R 1}
\end{array}\right.
$$

Residue $R_{d 8}: R_{d 8}(t)=\frac{D e_{3}-D e_{1}}{R_{C 2}}-C_{m 2} \frac{d D e_{3}}{d t}-D f_{5}-D f_{6}+w_{R C 2}+w_{C m 2}$

$$
\left\{\begin{array}{l}
R_{d 8}(t)=r_{8 n}(t)+d_{8} \\
r_{8 n}(t)=\frac{D e_{3}-D e_{1}}{R_{C 2}}-C_{m 2} \frac{d D e_{3}}{d t}-D f_{5}-D f_{6} \\
d_{8}=w_{R C 2}+w_{C m 2}
\end{array}\right.
$$

Residue $R_{d 9}: \quad R_{d 9}(t)=D e_{4}-R_{m 2} D f_{5}+w_{R m 2}$

$$
\left\{\begin{array}{l}
R_{d 9}(t)=r_{9 n}(t)+d_{9} \\
r_{9 n}(t)=D e_{4}-R_{m 2} D f_{5} \\
d_{9}=w_{R m 2}
\end{array}\right.
$$

Rsidue $R_{d 10}: R_{d 10}(t)=D e_{4}-M R_{2} D f_{6}+w_{M R 2}$

$$
\left\{\begin{array}{l}
R_{d 10}(t)=r_{10 n}(t)+d_{10} \\
r_{10 n}(t)=D e_{4}-M R_{2} D f_{6} \\
d_{10}=w_{M R 2}
\end{array}\right.
$$




\subsection{Faults in the hydraulic system}

In the thesis of Djeziri a fault at the level of the pipe (clogging) is considered as a parametric fault because it does not modify the structure of the system, but it changes the value of the element $(R: R n)$. So it is modeled in the same way as a multiplicative uncertainty, as a percentage of the nominal value of the parameter. On the other hand, a water leak in the tank is considered as a structural faultst since. The nominal model of the system is no longer respected and its dynamic is modified by the presence of the fault. This difference between the system and the model generates an imbalance in the mass and energy flow conservation laws computed from the 0 and 1 junctions of the bond graph model. The latter can be modeled by a flow source $S f$ : $Y i$ (figure 30).

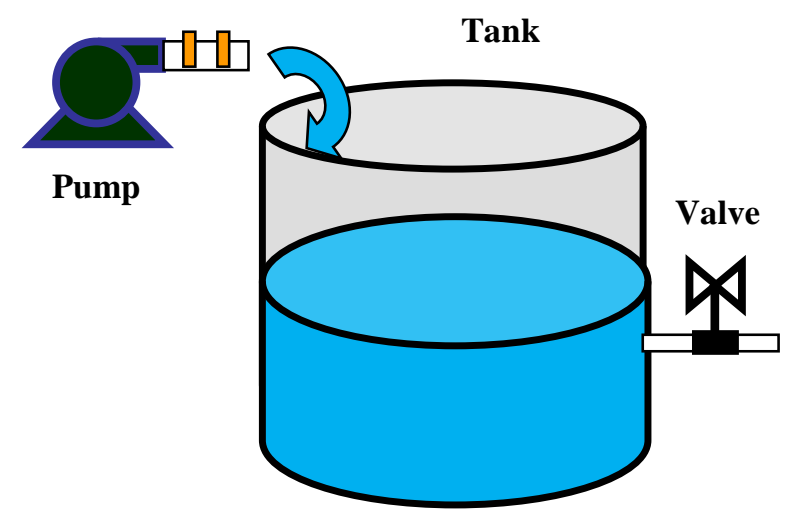

a)

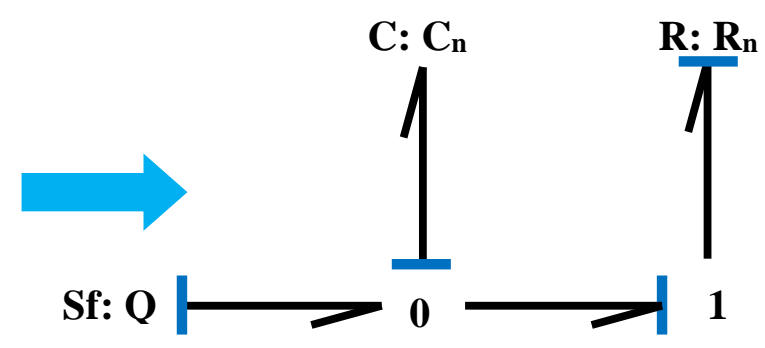

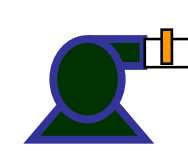

Pump

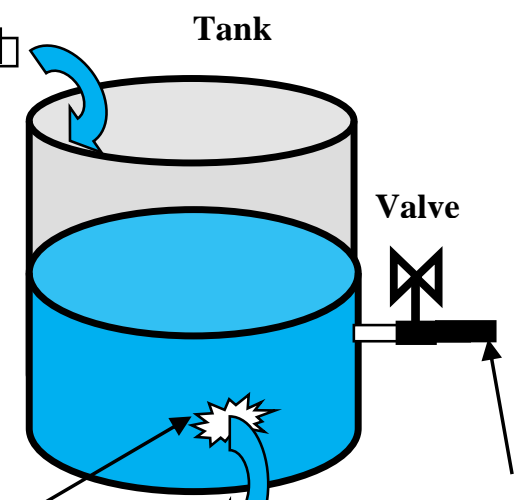

Parametric fault b)

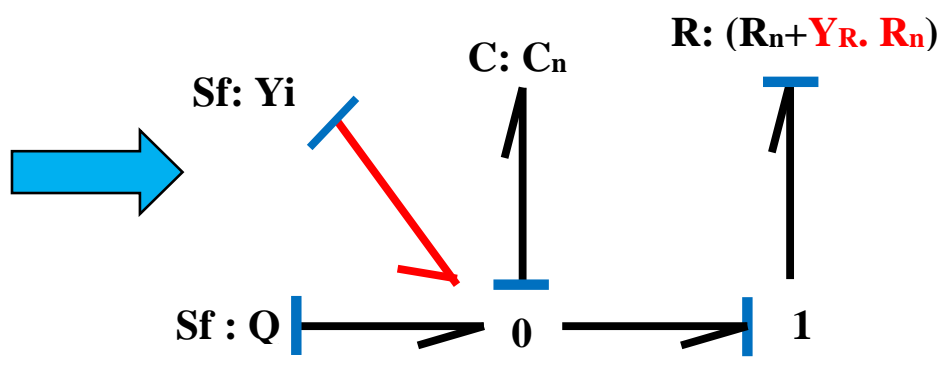

Structural fault

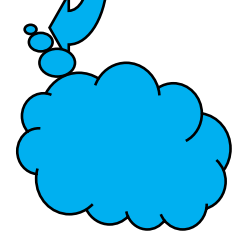

Figure.30. a): Physical models and bond graph model of a faultless system, b): Physical models and bond graph model of a system with a parametric and structural faults

\subsection{Determination of uncertain residues by the bond graph approach using the LFT model with faults}

In our case, there are three structural faults $\left(Y_{1}, Y_{2}\right.$ and $\left.Y_{3}\right)$ respectively at the $(\mathrm{Cu})$ reservoir and the two reverse osmosis $\left(R O_{1}\right.$ et $\left.R O_{2}\right)$ and fours parametric faults $\left(Y_{V 1}, Y_{V 2}, Y_{R m 1}\right.$ and $\left.Y_{R m 2}\right)$ at the two faults at the level of the pipe (plugging) for valves $\left(V_{l}\right.$ and $\left.V_{2}\right)$ and two faults in the membranes (clogging) for membrane $\left(R_{m 1}\right.$ and $\left.R_{m 2}\right)$ (see figure 31 ). 


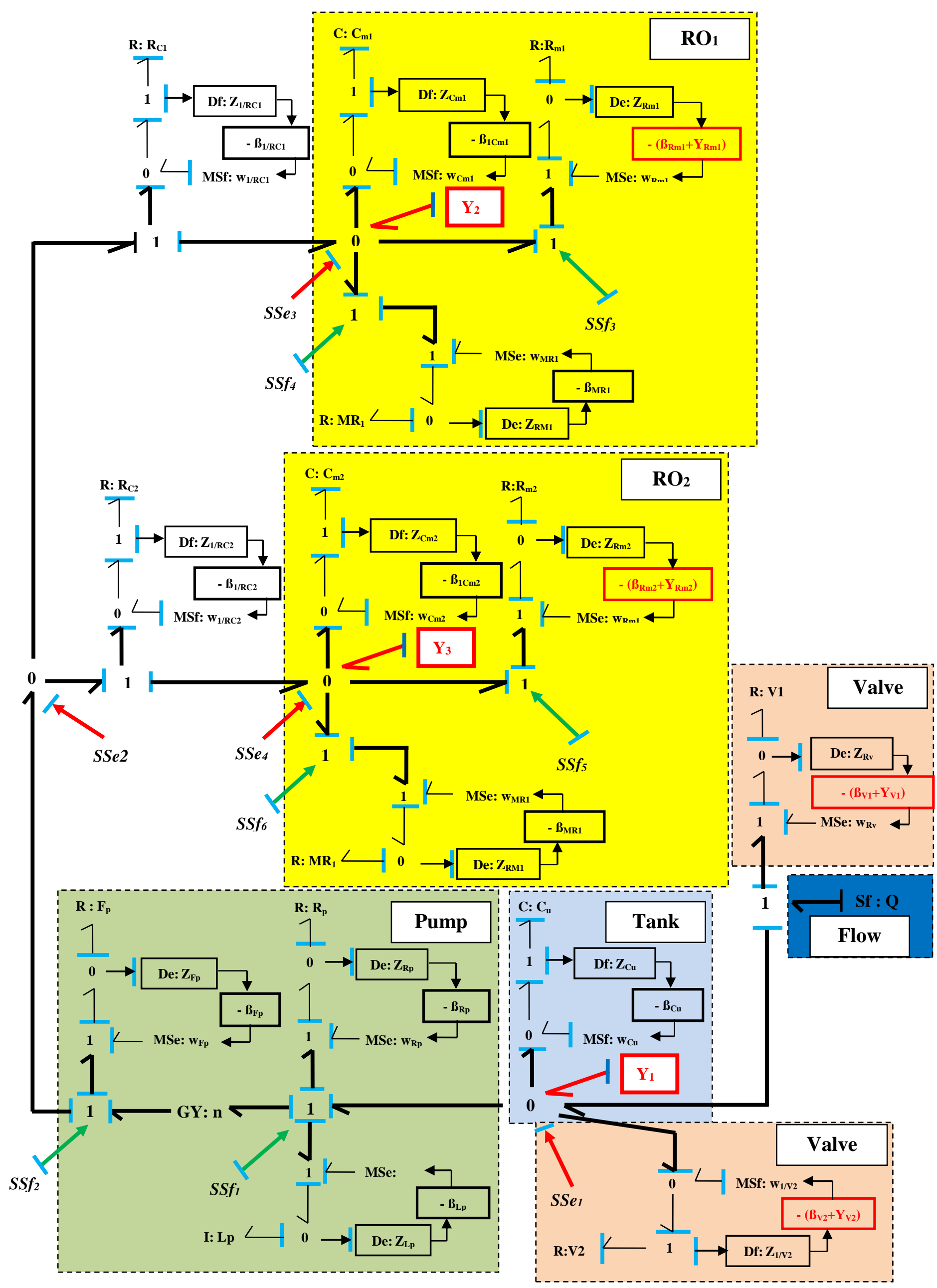

Figure.31. BG-LFT model of the desalination system in derived causality with faults 
6.9. Equations of uncertain residues by the bond graph approach using the LFT model with faults

$\checkmark$ Pumping system :

$>$ Residue $R_{d 1}: R_{d 1}(t)=Q-\frac{D e_{1}}{V}-C_{u} \cdot \frac{d D e_{1}}{d t}-D f_{1}+w_{V 2}+w_{C u}+Y_{1}+Y_{V 1}+Y_{V 2}$

$$
\left\{\begin{array}{l}
R_{d 1}(t)=r_{I n}(t)+d_{1} \\
r_{l n}(t)=Q-\frac{D e_{1}}{V}-C_{u} \cdot \frac{d D e_{1}}{d t}-D f_{1} \\
d_{1}=w_{V 2}+w_{C u}+Y_{1}+Y_{V I}+Y_{V 2}
\end{array}\right.
$$

Residue $R_{d 2}: \quad R_{d 2}(t)=D e_{1}-\frac{D e_{1}}{R_{p}}-L_{P} \cdot \frac{d D f_{1}}{d t}-m \cdot D f_{2}+w_{R P}+w_{L p}$

$$
\left\{\begin{array}{l}
R_{d 2}(t)=r_{2 n}(t)+d_{2} \\
r_{2 n}(t)=D e_{1}-\frac{D e_{1}}{R_{p}}-L_{P} \cdot \frac{d D f_{1}}{d t}-m \cdot D f_{2} \\
d_{2}=w_{R P}+w_{L p}
\end{array}\right.
$$

Residue $R_{d 3}: \quad R_{d 3}=m \cdot D f_{1}-D e_{1}-f_{p} D f_{1}+w_{f p}$

$$
\left\{\begin{array}{l}
R_{d 3}=r_{3 n}(t)+d_{4} \\
r_{3 n}(t)=m \cdot D f_{1}-D e_{1}-f_{p} D f_{1} \\
d_{3}=w_{f p}
\end{array}\right.
$$

Residue $R_{d 4}: \quad R_{d 4}(t)=D f_{2}-\frac{D e_{2}-D e_{1}}{R_{C 1}}-\frac{D e_{2}-D e_{4}}{R_{C 2}}+w_{R C 1}+w_{R C 2}$

$$
\left\{\begin{array}{l}
R_{4}(t)=r_{4 n}(t)+d_{4} \\
r_{4}(t)=D f_{2}-\frac{D e_{2}-D e_{1}}{R_{C 1}}-\frac{D e_{2}-D e_{4}}{R_{C 2}} \\
d_{4}=w_{R C 1}+w_{R C 2}
\end{array}\right.
$$

Residue $R_{d 5}: R_{d 5}(t)=\frac{D e_{2}-D e_{1}}{R_{C 1}}-C_{m l} \frac{d D e_{3}}{d t}-D f_{3}-D f_{4}+w_{R C l}+w_{C m l}+Y_{2}$

$$
\left\{\begin{array}{l}
R_{d 5}(t)=r_{5}(t)+d_{5} \\
r_{5 n}(t)=\frac{D e_{2}-D e_{1}}{R_{C 1}}-C_{m l} \frac{d D e_{3}}{d t}-D f_{3}-D f_{4} \\
d_{5}+w_{R C l}+w_{C m l}+Y_{1}
\end{array}\right.
$$


Residue $R_{d 6}: \quad R_{d 6}(t)=D e_{3}-R_{m l} D f_{3}+w_{R m l}+Y_{R m 1}$

$$
\left\{\begin{array}{l}
R_{d 6}(t)=r_{6 n}(t)+d_{6} \\
r_{6 n}(t)=D e_{3}-R_{m l} D f_{3} \\
d_{6}=w_{R m 1}+Y_{R m 1}
\end{array}\right.
$$

Residue $R_{d 7}: \quad R_{d 7}(t)=D e_{3}-M R_{1} D f_{4}+w_{M R I}$

$$
\left\{\begin{array}{l}
R_{d 7}(t)=r_{7 n}(t)+d_{7} \\
r_{7 n}(t)=D e_{3}-M R_{1} D f_{4} \\
d_{7}=w_{M R 1}
\end{array}\right.
$$

Rsidue $R_{d 8}: R_{d 8}(t)=\frac{D e_{3}-D e_{1}}{R_{C 2}}-C_{m 2} \frac{d D e_{3}}{d t}-D f_{5}-D f_{6}+w_{R C 2}+w_{C m 2}+Y_{3}$

$$
\left\{\begin{array}{l}
R_{d 8}(t)=r_{8 n}(t)+d_{8} \\
r_{8 n}(t)=\frac{D e_{3}-D e_{1}}{R_{C 2}}-C_{m 2} \frac{d D e_{3}}{d t}-D f_{5}-D f_{6} \\
d_{8}=w_{R C 2}+w_{C m 2}+Y_{3}
\end{array}\right.
$$

Residue $R_{d 9}: \quad R_{d 9}(t)=D e_{4}-R_{m 2} D f_{5}+w_{R m 2}+Y_{R m 2}$

$$
\left\{\begin{array}{l}
R_{d 9}(t)=r_{9 n}(t)+d_{9} \\
r_{9 n}(t)=D e_{4}-R_{m 2} D f_{5} \\
d_{9}=w_{R m 2}++Y_{R m 2}
\end{array}\right.
$$

Residue $R_{d 10}: \quad R_{d 10}(t)=D e_{4}-M R_{2} D f_{6}+w_{M R 2}$

$$
\left\{\begin{array}{l}
R_{d 10}(t)=r_{10 n}(t)+d_{10} \\
r_{10 n}(t)=D e_{4}-M R_{2} D f_{6} \\
d_{10}=w_{M R 2}
\end{array}\right.
$$




\section{CONCLUSION}

The integration of the external models and bond graph for the reconfiguration of the desalination system allowed us to extract the specifications of each model. The external models are used to structure the operation of the desalination process in several operating modes and to switch from one mode to another when a mission disappears. Bond graphs models clearly visualize the functions of the physical system (storage, dissipation, transfer) as well as the dynamics of the phenomena of the process and to trace the origins of the alarms by its causal organization. The next article will focus on the Robust Supervision by Luenberger Obsever Using Bond Graph Model of this system.

\section{REFERENCES}

[1]R.Merzouki, A.K.Samantaray, M.Pathak and B. Ould-Bouamama. Intelligent Mechatronic Systems: Modelling, Control and Diagnosis. Springer Verlag. 2013, ISBN: 978-1- 4471-4627-8, pp. 943.

[2]N. Chatti, A.L. Gehin, B. Ould Bouamama, R. Merzouki. Functional and behavioural models for the supervision of an intelligent and autonomous system. IEEE Transactions on Automation Science and Engineering. 2013, vol. 10, Issue ${ }^{\circ} 2$, pp. 431-445.

[3]W. Khalil and R. Merzouki, B. Ould Bouamama and H. Hafid. Hypergraph Models for System of Systems Supervision Design. IEEE Transactions on Systems. 2012, Man and Cybernetics, vol. 42, ${ }^{\circ}$ 4, pp. 1005-1012.

[4]R. Loureiro, R. Merzouki and B. Ould-Bouamama. Chapter 7: Structural Reconfigurability Analysis for an Over-Actuated Electric Vehicle. e-book-Mechatronic \& Innovative Applications, Bentham Science. ISBN: 9781608054404, e-book-Mechatronic \& Innovative Applications, 2012, pp. 127-146.

[5]T. K. Bera, R. Merzouki, B. Ould Bouamama and A.K. Samantaray. Design and validation of a reconfiguration strategy for a redundantly actuated intelligent autonomous vehicle. Journal of Systems and Control Engineering. 2012 sept, vol. 226, nº, pp. 1060-1076.

[6]A. K. Samantary, B. Ould Bouamama. Model-based Process supervision. Springer. 2008.

[7]K. Medjaher, A.K. Samantary, B. Ould Bouamama and M. Staroswiecki .Supervision of an industrial steam generator. Part II: On line implementation. Control Engineering Practice. 2006, Vol 14/1, pp. 85-96.

[8]A. Graisyhm. Méthodologie de conception des systèmes de supervision. Rapport Région Nord Pas de Calais, Mai, Valenciennes, France, 1998.

[9]P. Duthoit, J. Martin. La supervision: L’art de maitrise des processus. In: REE Nº7, 1997.

[10]M. Staroswiecki. La problématique et les approches de la surveillance des systèmes technologiques. Journées d'Etude S3: sûreté, surveillance, Supervision. Détection et localisation de défaillances. GDR automatique, 1994.

[11]J. P. Cassar, R. Litwak, V. Coquempot, V. et M. Staroswiecki. Approche structurelle de la conception de systèmes de surveillance pour les procédés industriels complexes. JESA, RAIRO-APII, 1994, pp.179-202.

[12]M. Imhemed, B. Conrard, M. Bayart, Génération de Code grâce au modèle externe pour un instrument

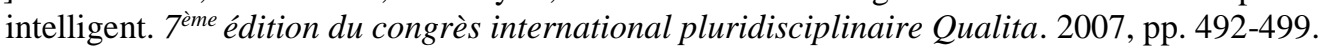

[13]S. Maza, M. Bayart M, B. Conrard, V. Cocquempot V. On the dependability design of complex Systems. $30^{\text {th }}$ ESReDA Seminar: Reliability of Safety-Critical System, SINTEF, Trondheim, Norway. June 2006.

[14]M. Bayart, E. Lemaire, M.A. Péraldi, C. André. External model and SyncCharts description of an automobile cruise control. Proc. IFAC Intelligent Components for Vehicle ICV'98. 1998, pp. 135-140.

[15]M. Bayart, E. Lemaire, M. A. Péraldi, C. André. External model and SyncCharts description of an automobile cruise control. Article étendu, Control Engineering Practice, Elsevier, octobre 1999. 
[16]A. SallamI, N. Zanzouri and B. Ould Bouamama .Robust Supervision of Industrials Systems by Bond Graph and External Models. International Journal of Enhanced Research in Science Technology \& Engineering. March 2016, ISSN: 23197463, Vol. 5 Issue 3.

[17]B. Ould-Bouamama. Contrôle en ligne d'une installation de générateur de vapeur par Bond Graph. Techniques de l'Ingénieurs AG3551. 28 pages 2014

[18]B. Ould-Bouamama. La conception intégrée pour la surveillance robuste des systemes. Approche Bond Graph. Techniques de l'Ingénieurs AG3550. 24 pages, 2013.

[19]A.K. Samantaray and B. Ould Bouamama. Model-based Process Supervision. A Bond Graph Approach. Springer Verlag, Series: Advances in Industrial Control. 2008, pp. 490, ISBN: 978-1-84800-158-9.

[20]B. Ould Bouamama, K. Medjaher, A.K. Samantary and M. Staroswiecki. Supervision of an industrial steam generator. Part I: Bond graph Modelling. Control Engineering Practice. 2006, CEP, Vol 14/1 pp. $71-83$.

[21]B. Ould Bouamama., M. Staroswiecki et Litwak R. Surveillance d'un générateur de vapeur. chap. 6. Collection IC2 Edition Hermes. Paris 2001, pp. 168-199.

[22]S. Benmoussa, R. Merzouki and B. Ould-Bouamama. Chapter 6: Bond Graph Model- Based Fault detection and Isolation: Application to Intelligent Autonomous Vehicle ebook- Mechatronic \& Innovative Applications, Bentham Science. 2012, ISBN: 9781608054404, pp. 111-126.

[23]A. Aitouche and B. Ould Bouamama. Detecting and Isolating Actuators Faults of Steam Boiler, International Journal of Sciences and Techniques of Automatic control \& computer engineering. 2008, IJSTA, Volume 2, W 2, pp. 764-775.

[24]B. Ould Bouamama, A.K. Samantary, K. Medjaher, M. Staroswiecki and G. Dauphin- Tanguy. Model builder using Functional and bond graph tools for FDI design. Control Engineering Practice. 2005, Vol. 13/7, pp. 875-89.

[25]R. Loureiro, S. Benmoussa, Y. Touati, R. Merzouki, B. Ould Bouamama. Integration of fault diagnosis and fault tolerant control for healthy monitoring of class of MIMO Intelligent Autonomous vehicles. IEEE Transaction on vehicular Technology . 2014, Vol. 63, Issue 1, DOI 10.1109/TVT.2013.2274289, pp. 30-39.

[26]Aitouche and B. Ould Bouamama. Sensor location with respect to fault tolerance Properties. International Journal of Automation and Control Inderscience Publishers. 2010, Vol.4, Issue 3, pp. 298-316.

[27]W. El Osta, C. Sueur et B. Ould Bouamama. Monitorability indexes for fault tolerance analysis using a bond graph approach". $6^{\text {th }}$ IFAC, SAFEPROCESS. 2006, pp. 1555-1560.

[28]M. Lienhardt, A. Aitouche , B. Ould Bouamama. Fault Tolerant Estimation for Multisensor Non linear Systems. International Mediterranean Modeling Multiconference (I3M), Proceedings edited by A. G Bruzzone et al. 2004, vol.2 pp. 177-181.

[29]T. B. Reiter. Human and computers roles in supervisory control and telerobotics. Musing about function, language and hierarchy. In L.P.Goodstein, H.B. Andersen, and S.E. Olsen, (Eds.) Task, errors and mental models. Taylor \& Francis. London. UK, 1988.

[30]J. Rasmussen. Skills, rules, and knowledge ; Signals, signs, and symbols and other distinction in Human Performance Models. IEEE transactions on systems man and sybernetics. 1983, Vol. SMC-13, №3, p 257, May/June 1983.

[31]M. Staroswieck et M. Bayart. Models and languages for the interoperability of smart instruments. Automatica. 1996, 32(6):859-873.

[32]Paynter H. M. Analysis and design of engineering systems. M.I.T. Press, 1961.

[33]G. Dauphin-Tanguy. Les bond graphs. HERMES Science Publications Paris. 2000, ISBN 2-7462-0158-5. 
[34]Ould Bouamama. B. Dauphin-Tanguy. G. Modelisation Bond Graph Element de base pour l'energetique. Technique de l'ingenieur. 2005, BE 8280.

[35]M. K. Hales, R. C. Rosenberg. Structured modelling of mechatronic components using multiport templates. Proceedings ASME IMECE. 2000, DSC- Vol.69-2, page 787-794, 2000.

[36]J. Zaytoon. Systèmes dynamiques hybrides. Hermes Science Publications, Paris, 2001.

[37]Redheffer. R, 1994. On a certain linear fractional transformation. EMJ. Maths Phys., 39: 269-286.

[38] Alazard. D, C. Cumer, P. Apkarian, M. Gauvrit and G. Fereres, 1999. Robustesse et Commande Optimale. 1st Edn., Cépadues-Editions, Toulouse, ISBN-10: 2854285166, pp: 348.

[39]Oustaloup, A., 1994. La robustesse. 1st Edn. Hermès, ISBN-10: 2.86601.442.1.

[40]SallamI. A, Zanzouri. N and B. Ould Bouamama «Robust Supervision of Industrials Systems by Bond Graph and External Models». International Journal of Enhanced Research in Science Technology \& Engineering ISSN: 23197463, Vol. 5 Issue 3, March 2016.

[41]A. Azmani, G. Dauphin-Tanguy. ARCHER: a program for computer aided modelling and analysis. Bond graph for Engineers. Ed. G. Dauphin-Tanguy and P. Breedveld, Elsevier Science Pub. 1992, pp. 263-278.

[42]M. Bayart et E. Lemaire. Intelligent formal description applied to hybridsystems. In IFAC, SICICA'97. 1997, pp. 715-720, Annecy, France.

[43]C. Maffezzoni, L. Ferrarini, E. Carpanzano. Object-oriented models for advanced automation engineering. In Symposium on Information Control in Manufacturing. INCOM'98. 1998, volume 1, pages 21-31, Nancy (France).

[44]M. Lind. Modeling goals and functions of complex industrial plants. Applied Artificial Intelligence. 1994, 8:258-283.

[45]B. Ould Bouamama. Fault detection and isolation of smart actuators using Bond graph and external models. Control Engineering Practice. 2004, Volume 13, $\mathrm{N}^{\circ} 2$, pp. 159-175.

[46]B. Ould Bouamama. G. Dauphin-Tanguy, M. Straoswcki, F. Busson. Bond Graph Technique as a DecisionMaking Tool in Supervision Systems. HKK Conference \& Symposium in Graph Theoretic \& Entropy Methods in Engineering, University of Waterloo. 1999, pp. 91-97. 